\title{
Padrões de Qualidade e Segurança Alimentares no Terreno Institucional Brasileiro*
}

\author{
Marcia da Silva Mazon
}

\section{INTRODUÇÃO}

$\mathrm{E}$ studiosos das ciências sociais abordam o tema dos mercados como uma construção político-cultural (Fligstein, 2001a, 2001b; Fligstein e Mara-Drita, 1996; Bourdieu, 2005), em particular o tema dos mercados alimentares (Steiner, 2006; Garcia-Parpet, 2003). Na leitura desta corrente - a Nova Sociologia Econômica (NSE) -, os mercados precisam de regras que são reforçadas pelo Estado para funcionar.

Questões como a emergência de instituições políticas e econômicas mobilizam também os autores próximos do paradigma da escolha racional; esse é o caso da Nova Economia Institucional (NEI). Nessa abordagem, os pesquisadores estão preocupados com a origem, a difusão e a estabilidade de novas formas organizacionais; eles veem o processo de institucionalização como difusão e manutenção de conjuntos de significados (Acheson, 1994; North, 1991). A referência ao modelo do ator racional implica que os atores coletivamente produzam instituições norteados pelos próprios interesses (Hall e Taylor, 2003). Para

\footnotetext{
* Agradeço à Coordenação de Aperfeiçoamento de Pessoal de Nível Superior (Capes) a bolsa de doutorado e ao Conselho Nacional de Desenvolvimento Científico e Tecnológico (CNPq) o financiamento do projeto Mercado, Empresa e Território no Brasil: Uma Construção Social, no qual se integra a presente pesquisa. Faço um agradecimento à Cecile Raud (in memoriam) e aos pareceristas anônimos desta revista pelas críticas e sugestões.
}

DADOS - Revista de Ciências Sociais, Rio de Janeiro, Vol. 52, n-4, 2009, pp. 1003 a 1045. 
essa corrente, as instituições que permanecem são as mais eficientes, argumento que pode ser estendido às análises disponíveis sobre a distribuição de alimentos: os autores leem o aumento da atuação privada (supermercados e indústria agroalimentar) como algo inevitável e necessário; o mesmo vale para a fragilidade das Centrais de Abastecimento (Ceasas), um projeto estatal no Brasil (Mainville et alii, 2005; Reardon e Farina, 2002). Para a NEI, nos momentos de crise, os resultados subótimos seriam substituídos por novos resultados buscados por atores que já têm interesses e preferências previamente dados (Théret, 2003).

A leitura da NSE discorda quanto à adequação do modelo do ator racional para explicar os fenômenos do mercado. Pesquisadores dessa corrente exploram o papel de instituições preexistentes na criação de novos arranjos institucionais. Segundo Fligstein (1990; 2001a; 2001b) e Bourdieu (2005), as instituições vencedoras refletem, antes, um ambiente conflituoso e a distribuição de poder na sociedade. As novas regras são o resultado de um processo político-cultural complexo, o qual produz acordos compartilhados que permitem os intercâmbios econômicos e produzem capacidades regulatórias para o Estado. As instituições preexistentes constrangerão e capacitarão os atores a se engajar em um comportamento cooperativo, e são as práticas culturais, mais do que os interesses (conscientemente calculados), que ditarão os acordos (Fligstein e Mara-Drita, 1996). Essas práticas estruturam o que é possível em uma dada situação, eliminando determinadas possibilidades e estabelecendo que ações são "razoáveis" (Bourdieu, 1996). Os contornos das instituições e organizações especificam quais atores podem propor e negociar acordos e como tais negociações se realizam (Skocpol, 1996), o que fornece às instituições um modelo de path dependency em que arranjos prévios servem de negociação para novos parâmetros e arranjos (Fligstein e Mara-Drita, 1996). A NSE propõe que os interesses dos atores não são fixos e que, em situações sociais fluidas, é possível que uma nova concepção de interesses tome forma. Como veremos, no Brasil e em outros países de baixa renda (PBRs), nas décadas de 1980 e de 1990, houve uma reversão de tendências no setor alimentar acompanhando mudanças ocorridas nos mercados europeu e norte-americano. Mudanças no varejo alteraram profundamente o atacado e também as condições enfrentadas pelos agricultores familiares (Reardon et alii, 2003; Reardon e Berdegué, 2002).

Neste artigo, a proposta é mobilizar a NSE e aplicá-la ao problema da construção das instituições do mercado alimentar. Seguimos o caso do 
abastecimento alimentar brasileiro, em particular das mudanças institucionais na distribuição de frutas, legumes e verduras (FLVs), à luz da abordagem político-cultural da NSE ${ }^{1}$ (Wanderley, 2002). Apontamos o papel da interatuação Estado e mercado, seja ao estimular determinados padrões, seja ao abandonar outros (Fligstein, 2001b).

O modelo de abastecimento alimentar para FLVs vigente hoje no Brasil foi pensado e executado na década de 1970, em uma perspectiva intervencionista e durante o regime militar. As Centrais de Abastecimento constituem o marco regulatório do abastecimento alimentar no país, sendo encarregadas da distribuição dos hortifrutigranjeiros. Essas empresas estatais assumiram, a partir de então, o papel de intermediação e de ponto de encontro entre produtores e seus clientes (atacadistas, supermercados, restaurantes, hotéis, entre outros).

Nas últimas décadas, ocorreu uma rápida transformação no setor de varejo alimentar nos países denominados em desenvolvimento, fenômeno acompanhado pela consolidação e pela multinacionalização do setor supermercadista (Reardon, Timmer e Berdegué, 2004). Houve uma mudança de mercados locais e fragmentados - mercados de bairro, mercearias, pequenos atacadistas - para supermercados amplos com centrais de compra próprias (Reardon, Henson e Berdegué, 2007). Essa mudança ocorreu, em primeiro lugar, com produtos secos, depois se estendeu ao setor de produtos frescos: FLVs, carne, peixe, ovos e leite. Há uma progressiva integração do mercado de produtos frescos com o surgimento do comércio de longa distância e o estabelecimento de áreas de produção especializadas (Reardon et alii, 2003). Essa integração demanda um alto investimento por parte dos produtores; processo promotor, por um lado, da criação de oportunidades e, por outro, da exclusão de pequenos produtores em países em desenvolvimento, somado ao aumento da concentração industrial (Reardon, Timmer e Berdegué, 2004; Wilkinson, 2004).

Análises do setor próximas à NEI leem o fenômeno como resultado, de um lado, de demanda de consumidores(as) urbanos(as) que, como trabalhadores(as) em tempo integral, motorizados(as) e com renda per capita superior, necessitam e podem trocar antigas práticas de cozinhar em casa por refrigeradores abastecidos mensal ou semanalmente com produtos prontos para o consumo ou pré-processados (lavados, picados e embalados) (Reardon et alii, 2003); esse pode ser o caso das FLVs (Wilkinson, 2002). Os atores que parecem melhor responder a essa de- 
manda - seja da regularidade da oferta, seja da qualidade dos frutos ofertados - são as grandes redes varejistas (Oosterveer, Guivant e Spaargaren, 2007). De outro lado, supermercados e indústria agroalimentar alcançaram uma redução secular nos preços dos alimentos processados (Reardon et alii, 2003).

Vários fatores são oferecidos para explicar a difusão dos grandes supermercados. Em primeiro lugar, os investimentos diretos estrangeiros (IDEs) são considerados um fator crucial (Wilkinson, 2004). O incentivo aos IDEs veio das redes varejistas europeias, norte-americanas e japonesas. Houve uma redução das margens de lucro nos países de origem e resultados mais favoráveis nos PBRs: o exemplo do Carrefour, na Argentina, com margens de lucro multiplicadas por três em comparação com as margens na França. Um segundo fator trata da revolução na estrutura logística de compra trazida pela ECR (efficient consumer response - resposta eficiente ao consumidor): gerenciamento de entrada e saída de mercadorias que minimiza os controles manuais e utiliza internet e computadores para controle de estoque, o qual aprimorou a coordenação entre fornecedor e varejista (Reardon et alii, 2003).

Nessa leitura, as Centrais de Abastecimento no Brasil foram deixadas para trás por sua falta de eficiência: incapacidade de atender a demanda e insuficiência logística; acrescenta-se a isso alto índice de perdas, embalagens inadequadas e armazenamento deficiente (Mainville et alii, 2005). No entanto, falta aos autores da NEI explicar de onde surgem novas instituições e como se tornam reconhecíveis como instituições apropriadas (Fligstein e Mara-Drita, 1996).

O foco deste artigo são os padrões de qualidade e segurança alimentar, por se tratar de um tema crucial para a distribuição de alimentos no momento atual. Nas últimas duas décadas, esses padrões para produtos alimentares surgem como tema central na agenda internacional por dois motivos: 1) o fato de produtos frescos (laticínios e FLVs) aparecerem como alternativa de renda para pequenos produtores graças ao valor agregado superior e à relativa ausência de economias de escala no setor (Reardon e Berdegué, 2002:371); 2) o setor de alimentos processados emerge como uma nova fonte potencial de exportação para países em desenvolvimento, como o Brasil. Entre os desafios para que esses países participem do mercado mundial está o de atender aos padrões de qualidade e segurança alimentares cada vez mais exigentes. A 
mudança na exigência está relacionada aos avanços científicos associados aos riscos à saúde, às melhorias na tecnologia do processamento alimentar e à cobrança do consumidor por padrões de segurança sanitária (Athukorala e Jayasuriya, 2003).

A NSE fornece uma estrutura analítica das condições sob as quais os padrões de qualidade e segurança alimentares privados emergiram e que ambiente deu origem a eles. Neste artigo, o objetivo é sugerir caminhos alternativos ao entendimento da interatuação Estado e mercado na nova conformação do mercado de FLVs a partir da década de 1980. Argumentamos que os padrões de qualidade e segurança alimentares não são fenômenos neutros; a própria definição desses termos exprime disputas culturais.

A análise exposta neste artigo implica que a NSE pode oferecer contribuições ao entendimento do processo de institucionalização e de construção do mercado alimentar. Os momentos de construção de instituições acontecem quando uma crise social, econômica ou política ameaça os arranjos institucionais antes estabelecidos (Fligstein, 2001b), como é o caso do Brasil no período da estagflação na década de 1980 e no novo ambiente da década de 1990 (Pereira, 1997; Marques, 1997). Nessas condições, atores coletivos estratégicos podem agir como empreendedores institucionais e tentar forjar novos arranjos. Os atores poderosos mais organizados podem ser convencidos de que novos arranjos são de seu interesse, mesmo que esses interesses sejam definidos e redefinidos no processo de negociação. Isso exige uma "estrutura cultural" que convence os atores sobre os contornos gerais dos novos arranjos (Fligstein, 2001a; Douglas, 1996; Grün 2003; 2005). No contexto da construção dos padrões de qualidade e segurança do mercado alimentar, mostramos como a perspectiva da NSE - enfatizando instituições sociais e relações entre elites e Estados - pode contribuir para o entendimento dos arranjos atuais.

As propostas da NEI e da NSE não estão necessariamente em oposição. Uma oportunidade política para criar instituições pode chegar a três resultados: nenhuma nova instituição, resultados racionalmente negociados (Acheson, 1994) ou a criação de uma nova estrutura cultural sob a qual papéis e regras são redefinidos (Fligstein, 2001b). Mesmo quando os acordos se realizam por meio da negociação racional eles estão enraizados no contexto social (Granovetter, 2003), em que há distribuição de poder e atores organizados (Bourdieu, 2005). 
O artigo está dividido em três seções. Na primeira seção, são apresentados os argumentos da NEI mobilizados no setor agroalimentar e a alternativa de leitura a partir dos autores da NSE. Em seguida, são situados os termos do debate da crise econômica da década de 1980, a revisão do papel do Estado e a origem dos padrões de qualidade e segurança alimentares. Na segunda, é mostrada a interatuação Estado e mercado no Brasil para esse setor a partir do histórico da crise que atingiu as Ceasas. Em seguida, o ambiente legal que permitiu tanto a entrada das redes varejistas multinacionais no país quanto o processo de concentração via incorporação de pequenas e médias redes supermercadistas é apontado. Por fim, são analisados aspectos da construção dos padrões de qualidade e segurança a partir do exemplo da distribuição do tomate no Brasil.

\section{OS NOVOS INSTITUCIONALISMOS E A CRIAÇÃO DE INSTITUIÇÕES}

Ao analisar o mercado, os novos institucionalismos próximos da escolha racional investigam a geração de instituições e os efeitos destas sobre as decisões e as performances econômicas (Acheson, 1994; North, 1991). Há duas formas de obtenção de bens/serviços por uma dada empresa: comprando de outras firmas no mercado ou produzindo-os internamente; oposição denominada hierarquia $x$ mercado (Acheson, 1994). Essas decisões implicam dois tipos de transações: as dentro da própria firma, que produzem custos de transação internos (honestidade dos empregados e confiança neles, graus de educação, práticas contábeis, entre outros) e a compra no mercado envolvendo os custos de transação externos (precisão na informação sobre preço, fornecedores regulares, contratos seguros, confiança na qualidade do bem, entre outros).

Os custos de transação externos são também influenciados pela eficiência de mercado, o que diz respeito ao atendimento das preferências dos consumidores e aos preços dos bens, se eles são adequados ao mercado. Se há ineficiência, os produtores não entram no mercado com o mix de produtos demandados, ocorrem superprodução, falhas e uma rápida flutuação de preços. A esse modelo a NEI acrescenta um conjunto de fatores sociais, culturais e econômicos que podem produzir os custos de transação em primeiro lugar (Acheson, 1994)2. North (1991) constata que os altos custos de transação internos e externos resultam em firmas de pequena escala, com horizonte de tempo curto e pequeno 
capital fixo; casos considerados típicos dos países em desenvolvimento.

Conforme os autores da NEI, os padrões de qualidade e segurança alimentares (G\&S, em inglês grades and standards), até há pouco tempo, eram considerados assunto exclusivamente de domínio público, e não objeto relevante estrategicamente para o setor privado ${ }^{3}$. Os G\&S nasceram com o mercado de commodities, geralmente como padrões públicos para reduzir custos de transação e aumentar a eficiência, permitindo a expansão do comércio ${ }^{4}$. Os padrões foram considerados bens públicos necessários na presença de imperfeições e de assimetrias informacionais, as quais podem causar falhas no mercado. Os debates recentes com relação à Organização Mundial do Comércio (OMC) focam os padrões como potenciais barreiras não tarifárias erigidas por governos como bloqueadoras de importações ameaçadoras para a produção doméstica (Reardon e Farina, 2002; Wilkinson, 2004).

Segundo a NEI, os padrões de segurança e qualidade desempenham papel fundamental no sentido de mitigar os custos de transação na cadeia alimentar (Holleran, Bredahl e Lokman, 1999). No caso dos produtos alimentares frescos, por sua característica particular de perecibilidade, existem restrições técnicas particulares que exigem o uso de tecnologias específicas, acentuando a importância de G\&S previamente estabelecidos (Mainville et alii, 2005).

Os padrões de qualidade e segurança alimentares privados são anunciados como a linguagem única para a circulação de produtos em um ambiente diagnosticado pela NEI como cada vez mais homogeneizado. O pressuposto é a exigência cada vez maior dos consumidores por esses padrões, além da alta concentração de mercado promovida pelas redes varejistas (as quais atendem de maneira eficiente os desejos do consumidor) em plano mundial (Athukorala e Jayasuriya, 2003).

Farina e Reardon (2000) destacam como singularidade do caso brasileiro uma rápida concentração em cadeias de produtos-chave e, consequentemente, a exclusão de pequenas firmas e produtores com o rápido crescimento de economias alimentares de exportação e domésticas. Os padrões privados desempenham um papel fundamental no que esses autores denominam de um "boom com exclusão" na economia alimentar (Farina e Reardon, 2000). Reardon e Berdegué (2002:385) anunciam que a distinção entre mercado global/de exportação e mercado local/doméstico está prestes a desaparecer, sugerindo às agências de 
fomento, aos programas de desenvolvimento e às políticas públicas em geral a urgente necessidade de articulação com supermercadistas gigantes caso queiram encontrar alternativas para pequenos produtores.

Analisando o caso do Mercosul, Reardon e Farina (2002) afirmam o contexto das trocas comerciais, das quais os países do bloco (Argentina, Brasil, Paraguai e Uruguai) participavam na década de 1990, como exigente com relação a estratégias específicas das firmas para sobrevivência no mercado: era necessário diferenciar os produtos e identificar nichos. Nesse contexto, os G\&S eram fundamentais para tal diferenciação. Entretanto, onde o setor agroalimentar desenvolveu estratégias privadas de diferenciação dos produtos, os governos do Mercosul (individual ou coletivamente) se atrasaram na criação e na harmonização dos G\&S. Em alguns casos, padrões públicos até existiam, mas sua forma e/ou seu nível de especificidade não alcançavam as necessidades dos atores do sistema agroalimentar privado; eram antes percebidos como obstáculos às negociações (ibidem:15).

A rede varejista constrói padrões de segurança e qualidade que superam, segundo essa corrente, os padrões públicos tradicionais. A tendência observada a partir da década de 1990 nos países ocidentais é a de venda altamente padronizada e de empacotamento com selos identificadores da rede varejista (Oosterveer, Guivant e Spaargaren, 2007). Conforme os autores, o Brasil acompanha essas tendências mundiais de alimentos mais saudáveis na cadeia de distribuição.

Questionando a teoria da escolha racional, os autores da NSE - ao retomarem Durkheim e Weber - analisam como as instituições organizam as relações sociais e as atividades econômicas (Raud-Mattedi, 2005:130). Isso ocorre não apenas porque as instituições regulamentam os conflitos de interesse, mas sobretudo porque permitem a constituição de novos interesses (Fligstein e Mara-Drita, 1996). Com relação à interação entre instituições e comportamentos individuais, autores como Bourdieu, Fligstein e Douglas enfatizam a dimensão cognitiva das instituições. Elas forneceriam esquemas, categorias e modelos cognitivos indispensáveis à ação, não especificando somente o que se deve fazer, mas também o que se pode imaginar fazer em um contexto dado. Influenciam não apenas os cálculos estratégicos dos indivíduos mas também suas preferências (Raud-Mattedi, 2005). A ênfase é sobre a natureza interativa das relações entre as instituições e a ação indivi- 
dual: para agir, o indivíduo utiliza os modelos institucionais disponíveis ao mesmo tempo que os confecciona (Douglas, 1996).

Na sociologia econômica weberiana, a relação mercantil é uma relação social na medida em que os atores devem levar em conta não somente o comportamento dos outros atores econômicos mas também o contexto sociopolítico. São os interesses próprios que orientam a atividade econômica e também a ação futura e previsível de terceiros e "'ordens' que o agente conhece como leis e convenções 'em vigor'” (Weber, 2004:420).

Para a NSE as instituições afetam a imagem de si, a identidade do ator econômico, configurando visões de mundo que legitimam determinados fins e meios da ação social (Théret, 2003). A legitimação de certos arranjos institucionais pode ser explicada pela expansão do papel regulador do Estado que impõe várias práticas às instituições, conforme proposta de Fligstein $(1990 ; 2001 b)$, ou ainda a crescente profissionalização de esferas de atividade engendrando comunidades profissionais dotadas de autoridade cultural suficiente para impor a seus membros certas práticas (Dimaggio e Powell, 1991). Há aqui um rompimento com a dicotomia instituições / cultura. Bourdieu (2005), retomando Weber, afirma que há uma intersecção entre o campo político, jurídico e econômico; as leis são estabelecidas pelo Estado, pressionado pelos atores dominantes.

Com relação ao caráter da eficiência, para a NEI, quanto mais ganhos resultantes da troca, mais a instituição será robusta, de modo que sobrevivem as instituições mais eficientes. Para a NSE, as instituições refletem a forma de distribuição de poder em uma dada sociedade e são práticas culturais (Hall e Taylor, 2003). A análise da NSE nos permite observar como se confere a um arbitrário cultural, como os padrões de qualidade e segurança alimentares, "toda a aparência do natural" (Bourdieu, 1993:50). Nesse sentido, as análises do sistema agroalimentar com o enfoque da NSE chamam a atenção para os processos sociais e políticos mobilizados na construção histórica de mercados, como o dos morangos de mesa (Garcia-Parpet, 2003) na França. Outra corrente teórica que se encaixa na NSE é a sociologia relacional, inspirada em Simmel, que foca as atribuições dos diversos atores (produtores, intermediários, consumidores) e como os critérios que autorizam a circulação de bens e serviços no mercado podem surgir de pontos diferentes da cadeia (Cochoy, 2002). Esses trabalhos vislumbram os distribuido- 
res que põem em movimento lógicas que se destinam a favorecer a circulação por meio da homogeneização dos produtos alimentares por um lado e, por outro, mostram os produtores pressionando por uma identificação do produto heterogêneo, forçando o mercado a lidar com um produto com uma pluralidade de qualidades (Dubuisson-Quellier, 2003). Dubuisson-Quellier mostra como, no caso dos moluscos franceses, em uma situação de indeterminação do mercado, os distribuidores estabeleceram a lógica da homogeneização. Voltaremos ao tema a seguir.

\section{Crise, Reforma do Estado e a Circulação dos Alimentos}

Aqui é ressaltado o período de 1940 a 1960, dominado pelo paradigma do Estado de bem-estar social. A maioria dos economistas do desenvolvimento defendia como os governos, em mercados que funcionassem de maneira imperfeita, tal qual os dos países em desenvolvimento, deveriam comportar-se como guardiões sociais e que aos burocratas cabia formular e programar modelos de planejamento. A coordenação e a administração do setor público eram consideradas algo gratuito. Considerações sobre eficiência não deveriam ser obstáculos caso a empresa pública fosse uma possibilidade de escolha para a promoção do desenvolvimento de um país (Krueger, 1990).

Na esteira da inflação, do desemprego e da corrupção das duas décadas seguintes, os analistas apontam as debilidades institucionais, financeiras e organizacionais do setor público (Pereira, 1997). Krueger considera o fracasso governamental superior aos fracassos do mercado, enumerando falhas de omissão e de comprometimento. Essa autora afirma que os programas de investimento governamentais são ineficientes e perdulários, assim como o controle governamental sobre atividades do setor privado é difuso e custoso (Krueger, 1990).

A partir daí, constata-se uma nova orientação para a ação governamental: a ideia da intervenção estatal é substituída pela da eficiência e da eficácia no setor público. As bases teóricas dessas reflexões podem ser encontradas na NEI: esses autores defendem a eficiência das estruturas empresariais como motor explicativo central das formas organizacionais (estratégias de diversificação, verticalização, redução de custos, ganhos de escala); a eficiência econômica é central para o entendimento do dinamismo das empresas, que reagem aos sinais de mercado. Autores como North argumentam que, por razões políticas, o Esta- 
do tende a criar direitos de propriedade que são ineficientes por constranger o desenvolvimento econômico e contribuir inadvertidamente para o aumento dos custos de transação para os atores econômicos. North (1991) observa que atores privados respondem estrategicamente ao crescimento lento da construção de organizações econômicas que reduzem os custos de transação e melhoram o desempenho econômico. Para North (ibidem), a própria manipulação dos direitos de propriedade pelo Estado cria pressões por mudanças organizacionais.

No Brasil, as reformas serão pautadas pela descentralização - fortalecimento da autonomia administrativa, financeira e decisória do governo local - e pelo accountability ${ }^{5}$ - desempenho do serviço público associado à resposta fiscal e financeira do governo (Pereira, 1997). O modo de administração tradicional da burocracia foi condenado e o modelo do mercado, anunciado como virtuoso (Grün, 2005).

Há ainda neste momento para os países em crise inflacionária uma forte dependência do financiamento externo; a reforma proposta passa a ser modelada pelas agências multilaterais: Banco Mundial, Banco Interamericano de Desenvolvimento (BID), Fundo Monetário Internacional (FMI), entre outros (Tavares de Almeida, 1999). A reforma do Estado só existiria se passasse pela redução da influência do governo no mercado e pelo aumento da eficiência burocrática, a ideia do "Estado mínimo". As políticas elaboradas no Consenso de Washington foram posteriormente aplicadas no âmbito da OMC: políticas macroeconômicas restritivas, liberalização do comércio internacional e dos investimentos, privatização e desregulamentação, defesa da melhoria na entrega de serviços por intermédio da terceirização, entre outras (Pereira, 1997).

De fato, no Brasil, a partir da década de 1980, as instituições privadas passaram a ser vistas como a solução para os problemas do aparato público (Marques, 1997). Dentro da agenda de reformas estabelecida para tal período, a privatização das empresas públicas foi o item que mais avançou no país (Tavares de Almeida, 1999). No setor de distribuição alimentar, observaram-se o fortalecimento de instituições privadas (supermercados) e o sucateamento das instituições públicas (Ceasas); as últimas estão incluídas na lista do Plano Nacional de Desestatização.

As análises apontam para a falta de infraestrutura das Ceasas, sua debilidade logística e ineficiência para responder às demandas da rede 
supermercadista e dos novos consumidores (Mainville et alii, 2005). No momento atual, os termos apresentados para a chamada "Reforma do Estado" e o caminho das privatizações são questionados (Pereira, 1997). O caráter de evidência da eficiência das instituições privadas está em pleno debate: o movimento chamado de financeirização ${ }^{6}$ foi questionado, no caso americano, por Fligstein (2001a); no caso brasileiro, por Grün (2003); no caso mexicano, por Hisham Aidi (apud Pereira, 1997) ${ }^{7}$.

O Estado, outrora o guardião da sociedade, passa a ser analisado em concepção e linguagem financeiras - isto é o que Fligstein (2001a; 2001b) define como uma "concepção de controle". O autor (2001a) mostra a emergência da concepção de controle da financeirização nos Estados Unidos como resposta à crise econômica da década de 1970. No mesmo sentido, a emergência do Mercado Comum Europeu (MCE) ocorre como resposta à crise do início dos anos 1980 na Europa, a chamada "Eurosclerosis" (Fligstein e Mara-Drita, 1996).

Fligstein (2001a) observa, nos Estados Unidos, como a aderência por parte das empresas ao sinal do "valor acionário" não as tornou mais lucrativas que outras, assim como também não promoveu a recuperação de suas posições anteriores no mercado, perdidas para o Japão e para a Europa (eletrônicos, automóveis e produtos de luxo); as empresas financeiramente reorganizadas serviram para transferir riqueza dos trabalhadores aos dirigentes e aos acionários. Além disso, a "desregulamentação" (expressão contraditória para esse autor) não significou o fim da intervenção do Estado no mercado, ao contrário, o Estado forneceu a infraestrutura institucional necessária à maximização do valor acionário por sua regulação dos mercados financeiros (incentivos fiscais e financiamento das fusões).

O abastecimento alimentar brasileiro é um exemplo ímpar desse questionamento. $\mathrm{O}$ processo chamado de globalização tem aumentado o número de conexões entre os diversos países em termos do intercâmbio de bens, tecnologia, serviços e difusão dos veículos de mídia de massa. Isso aconteceu com o processo de concentração da indústria alimentar e do varejo. As transformações foram iniciadas na segunda metade do século XX e aceleradas no coro entoado pelos países de alta renda para uma abertura dos mercados nesses termos. Nesse período, agências multilaterais, como o FMI e o Banco Mundial, acompanhadas da maioria dos países de alta renda, promoveram a agenda do livre-co-

\section{4}


mércio como panaceia para os males dos países de baixa renda (Popkin, 2006).

\section{A Visão Sociológica dos Mercados}

Fligstein e Mara-Drita (1996) observam que a definição corrente do mercado é a de uma situação social na qual a troca de um bem ocorre e há um mecanismo de preço que determina o valor dele. Esse mecanismo de preço implica a existência de dinheiro e a quantidade necessária deste para o pagamento do bem. Retomando Weber (2004), esses autores acrescentam que isso não especifica como a arena de troca ou o mecanismo de preço (eles mesmos) operam nem sugere uma estrutura para as relações sociais que passarão a existir entre fornecedores, produtores, consumidores e Estado.

A existência do mercado supõe relações sociais elaboradas, que devem surgir para estruturar a arena de troca. Elas se referem a regras compartilhadas, leis ou entendimentos coletivos, mantidos pelo costume, por um acordo explícito ou implícito. As instituições que permitem uma visão sociológica do mercado, na proposta de Fligstein (2001b), são os direitos de propriedade, as estruturas de governança, as regras de troca e as concepções de controle. Elas são apresentadas a seguir a fim de situar o desenho atual do mercado alimentar.

Fligstein (2001a) apresenta uma visão sociológica do mercado na forma de uma metáfora: a metáfora do "mercado como política", como um "movimento social" em duas dimensões. Na primeira dimensão, ele rompe com a ideia do ator racional ao afirmar que "os atores do mercado habitam mundos obscuros, onde nunca está claro quais ações terão quais consequências" (Fligstein, 2001b:31). As empresas querem, antes de maximizar seus lucros (já que nenhuma delas sabe quais serão as consequências de seus atos), montar um mundo estável no qual as regras objetivam evitar uma guerra aberta, permanecendo em seus ni$\operatorname{chos}^{8}$. Nesse sentido, as maneiras de proceder das empresas mudam de acordo com as decisões políticas e o direito econômico. Essas "maneiras de proceder" seriam as concepções de controle: os mercados produzem culturas locais que definem quem é um estabilizado e quem é um desafiador; definem, nesse sentido, uma estrutura social: "Elas [as culturas locais] prescrevem como a competição vai operar em um dado mercado. Elas também fornecem aos atores estruturas cognitivas para 
interpretar a ação das outras organizações" (Fligstein, 2002:15; tradução da autora).

Para demonstrar essa hipótese, Fligstein (1990) analisa um conjunto de cem empresas nos Estados Unidos, desde o final do século XIX até a década de 1990, e mostra que a maneira de evitar a concorrência muda conforme as decisões políticas, alternando diferentes concepções de controle: no século XIX, prevalecem os monopólios e os cartéis, as empresas exercem controle direto sobre os concorrentes - o direct control. Isso acaba com o Sherman Act (1890). O início do século XX é o momento da ênfase na integração técnica (verticalização) para limitar incertezas e assegurar economias de escala e rentabilidade; os profissionais valorizados são os engenheiros, é o período do manufactoring control. Depois dos anos 1920, há uma ênfase na comercialização, na reorganização das empresas por produto, na segmentação; é o momento do marketing e das vendas. A última concepção é a do controle financeiro: no quadro da desregulamentação financeira, surge uma nova concepção financeira na década de 1980; o foco é a taxa de lucro máxima ao acionista. As empresas são cotadas na Bolsa de Valores, e os conselhos administrativos das empresas obedecem ao valor acionário denominado shareholder value.

As firmas contam com governos e cidadãos para produzir mercados, e sua habilidade para produzir mundos estáveis depende, em grande parte, desses relacionamentos (Fligstein, 2001b).

A segunda dimensão da metáfora diz respeito à relação do Estado com o mercado: a formação deste faz parte da formação do Estado, que apoiou, ao longo do século XX, nos Estados Unidos, em diferentes ambientes legais, as concepções de controle predominantes.

Na fase da financeirização, Fligstein (ibidem) aponta a criação da legislação de proteção ao direito dos acionistas, a existência de práticas contábeis e o lançamento de oferta de compra. O Estado também promoveu a desregulamentação do mercado de trabalho e dos transportes rodoviário e aéreo nas décadas de 1970 e 1980 como forma de enfrentamento da estagflação. O governo Reagan propôs uma nova política de concorrência para fortalecer as empresas nacionais, afrouxando leis antitrustes e diminuindo o imposto sobre os lucros, medidas que incentivaram as fusões/aquisições. 
Os direitos de propriedade dizem respeito às definições e ao controle de propriedade. Patentes e práticas de certificação também são direitos de propriedade, pois dão garantia exclusiva aos portadores das práticas e dos ganhos dessas designações (Fligstein e Mara-Drita, 1996). Para o mercado alimentar, nas últimas décadas as tecnologias de informação e comunicação (TICs), somadas às novas biotecnologias, constituem o novo paradigma tecnológico em substituição à tecnologia intensiva em capital e energia (Wilkinson e Castelli, 2000). Abordaremos a Lei de Patentes e a Lei de Proteção de Cultivares no Brasil para analisar um aspecto dos direitos de propriedade.

A constituição desses direitos é um processo político contestável, no qual Estados, trabalhadores, comunidades locais, fornecedores e clientes podem intervir na forma como proprietários podem dispor da propriedade (Fligstein, 2001b). Em todas as sociedades, comunidades locais podem confiscar propriedades e impedir a livre agência dos proprietários; este é o caso da regulação ambiental ou das leis de zoneamento (Fligstein e Mara-Drita, 1996). Voltaremos em breve a esse tema para apresentar o zoneamento agrícola e a produção de tomates no Brasil.

Estruturas de governança se referem às leis e às práticas informais que situam os limites da competição legal e da cooperação: leis antitrustes, políticas de competição, regras sobre formas legais e ilegais de cooperação, como cartel, joint ventures e fusões. Voltamos a elas para falar das mudanças atuais no mercado alimentar e da emergência das grandes redes supermercadistas no Brasil. Regras de troca facilitam a substituição pelo estabelecimento de regras sob as quais as transações são garantidas; definem quem troca com quem; dão a garantia de que os bens serão entregues dentro de uma ordem e serão pagos promovendo a circulação por meio da construção de regras mais simples, mais claras e de menor custo (idem, ibidem:15). Essas categorias conceituais estão ligadas de diferentes maneiras e estão separadas apenas analiticamente para a compreensão da construção dos diferentes mercados (ibidem). Voltamos às regras de troca para falar da construção do mercado das FLVs, da atuação das Ceasas e da construção dos padrões de segurança e qualidade alimentares. Fligstein e Mara-Drita (1996) constatam as regras de troca como o item principal na construção do MCE, apresentado a seguir. 


\section{Uma Possível Origem dos Padrões de Qualidade e Segurança}

Os padrões de qualidade e segurança alimentares são de duas ordens: pública e privada. De um lado os padrões nacionais administrados pelo poder público em diferentes países procuram assegurar aos consumidores que os produtos que chegam à ponta final da cadeia sejam seguros; busca-se sua "traçabilidade" desde a produção até a chegada às bancas nos supermercados e feiras. Há também iniciativas multilaterais, como a criação do Codex Alimentarius ${ }^{9}$. Os padrões de qualidade e segurança podem partir da iniciativa privada, como é o caso da ISO 9000. Este é um procedimento internacionalmente reconhecido e que serve como guia no sentido de estabelecer os G\&S (Holleran, Bredahl e Lokman, 1999).

Conforme mostram Fligstein e Mara-Drita (1996) com relação à globalização, em virtude do processo político-cultural do mercado, os países não estão convergindo em direção a uma forma única de organização industrial eleita como "a mais" eficiente. As interações entre empresas e Estados produzem "culturas produtivas" únicas. De maneira semelhante, para o mercado alimentar, Wilkinson (2004) mostra que o direcionamento dos IDEs não constitui um movimento único; tanto os pontos de origem (Estados Unidos, União Europeia (UE) e Japão) quanto os pontos de chegada desses investimentos (entre eles os países em desenvolvimento) são marcados por padrões complexos e distintos de interatuação Estado e mercado. Esses padrões incluem mudanças específicas nas legislações dos respectivos países no sentido de estimular a entrada dos IDEs como uma variação dos produtos em foco.

O exemplo da criação do MCE mostra como a globalização não reduz o papel do Estado. A emergência dos mercados globais depende da cooperação entre as firmas e os Estados para produzir as regras do jogo. Fligstein e Mara-Drita (1996) mostram como uma estrutura cultural forneceu as bases para a constituição de diversos acordos que culminaram na estrutura do MCE.

Em 1985, a UE decide completar a unificação do MCE até 1992. Os objetivos gerais da reforma foram promover o comércio, aumentar a competitividade e promover uma grande economia de escopo e de escala, eliminando barreiras não tarifárias, tais como diferenças em taxas, regulações e padrões de segurança e sanidade. As diretivas (279 mais duas acrescentadas no final) são relativamente heterogêneas em seu conteúdo, escopo e importância (ibidem). 
Fligstein e Mara-Drita mostram ainda que o mercado desenhado no projeto do MCE de 1992 tinha como intuito facilitar as trocas para empresas que já estavam exportando e preservar o poder do Estado de controlar os direitos de propriedade e governança onde eles já existiam. O MCE não criou uma nova capacidade regulatória europeia. Tão somente o mercado foi aberto onde suas indústrias estavam preparadas para essa integração ${ }^{10}$, o que diz respeito ao setor de transporte, prestação de serviços, tanto financeiros quanto de negócios. Uma das hipóteses de Fligstein e Mara-Drita (ibidem) é que os direitos de propriedade e as estruturas de governança não foram o foco do MCE. A maioria das diretivas foi orientada para as regras de troca, já que um dos pontos críticos do MCE foi encontrar uma estratégia de fluxo das negociações na garantia do estabelecimento da confiança nas trocas: um mercado comum implicaria um conjunto de regras para todos os atores, conformados a um mesmo padrão. Se cada Estado preferisse preservar sua soberania e mantivesse os próprios padrões já desenvolvidos, as negociações seriam restritas (ibidem). Veremos como a entrada do Brasil no mercado mundial de alimentos difere do movimento do MCE. Aqui no Brasil, as estruturas de governança e os direitos de propriedade foram alterados e as regras de troca, mantidas.

Antes de 1980, a negociação sobre a abertura dos mercados no âmbito da UE era um processo cansativo, já que os acordos eram muito detalhados e exigiam anos para definir produtos e padrões possíveis. Isso mudou nos anos de 1980 com a decisão da corte sobre o caso Cassis de Dijon (ibidem). O Tribunal de Justiça Europeu dispensou a mobilização de padrões próprios para os produtos; todos os bens e serviços legalmente produzidos por um Estado-membro deveriam ser aceitos pelos demais. Essa estratégia, denominada "reconhecimento mútuo", tem a característica fundamental de permitir simultaneamente que os países abram o comércio para bens e serviços sem comprometer suas próprias definições de produtos.

A UE resolveu utilizar o reconhecimento mútuo como um princípio das negociações de mercado aberto. A decisão do caso Dijon tornou possível para os Estados impedirem a entrada de produtos ou serviços em seus países caso eles sentissem que padrões de sanidade e segurança estivessem em risco. A UE percebeu que a abertura do mercado teria de focar a harmonização de padrões de sanidade e segurança por meio das sociedades. Essa concepção, que Von Sydow (1988 apud Fligstein e Mara-Drita, 1996) chama de "nova harmonização", é o empreendi- 
mento para estabelecer padrões coletivos para sanidade, segurança ou padrões técnicos comuns para todas as nações.

A análise apresentada por Fligstein e Mara-Drita (1996) nos permite sugerir a possibilidade dos padrões de qualidade e segurança alimentares como uma construção cultural. Um arranjo prévio do MCE pode ser a inspiração nas negociações dos parâmetros e arranjos elaborados na América Latina, embora com uma distinção com relação às instituições em foco. Passemos para a análise mais detalhada do caso brasileiro dos produtos frescos à luz das instituições propostas por Fligstein.

\section{CENTRAIS DE ABASTECIMENTO E SUPERMERCADOS: ENTRE ESTRUTURAS DE GOVERNANÇA, DIREITOS DE PROPRIEDADE, REGRAS DE TROCA E CONCEPÇÕES DE CONTROLE}

Apresentamos a seguir o histórico das Ceasas e o terreno institucional para o estabelecimento dos padrões de segurança e qualidade.

A história da produção e da distribuição de gêneros alimentícios no Brasil é marcada por crises que exprimem as disputas entre produtores, de um lado, e atacadistas e distribuidores, de outro. Em todas as situações, o ganho é para os atacadistas e distribuidores (Linhares e Silva, 1979).

No período das Primeira e Segunda Guerras Mundiais, os atacadistas priorizam a exportação de gêneros alimentícios para os países beligerantes, e o mercado interno é atingido por várias crises de desabastecimento; a intervenção do Estado se dá no sentido de contornar essas crises, mas sempre em caráter emergencial. Com a expansão industrial, a área dedicada à produção de gêneros alimentícios voltada para o mercado interno perde terreno para a lavoura especializada na produção de matéria-prima. No ano de 1918, no quadro da República Velha, cria-se o Comissariado de Alimentação Pública, primeiro órgão a marcar a intervenção do Estado no problema do abastecimento. $\mathrm{O}$ aumento das exportações (destaque para arroz, feijão e carne) é acompanhado pelo aumento estratosférico dos preços em virtude da contenção dos estoques por parte dos monopolistas da distribuição (idem, ibidem).

Os trustes dos setores de sacaria, tecidos, algodão, açúcar e sal se aproveitavam dos momentos de crise para aumentar os preços, e os atacadistas faziam amplos estoques de gêneros alimentícios nos trapiches dos portos do Rio de Janeiro à espera da alta. O Comissariado foi cri- 
ado pelo Decreto-Lei no 13.069/1918. Embora com atuação precária, foi alvo de críticas da elite comerciante ${ }^{11}$, incluindo também atravessadores, produtores, além de deputados, usineiros, charqueadores, fabricantes de bebida e beneficiadores de milho e algodão. Os críticos defendiam o liberalismo e criticavam o uso de tabelamento e de racionamento como um "retorno à Idade Média" (ibidem:46). Com relação às concepções de controle (Fligstein, 1990) para o caso norte-americano, este seria o correspondente do período dos cartéis, do controle direto da concorrência, o direct control.

Houve uma pressão pelo fim do Comissariado e o governo criou a Superintendência de Abastecimento por meio da Lei no 4.039 de janeiro de 1920, regulamentada pelo Decreto no 14.027/1920. A Superintendência extingue o controle sobre as exportações, acaba com o tabelamento de preços e organiza um acordo para o fornecimento de gêneros alimentícios aos centros urbanos. A liberação da entrada de produtos estrangeiros, como sal, batata, arroz, feijão, manteiga, milho e charque, agiliza o comércio de mantimentos por intermédio da criação do Decreto $\mathrm{n}$-16.633/1924, que amplia os prazos de isenção sobre os gêneros alimentícios (Linhares e Silva, 1979).

A Superintendência também colaborou na organização de cooperativas e feiras livres nas principais capitais (idem, ibidem:54). O problema do abastecimento apontava para a necessidade de criação de uma forma de circulação de gêneros alimentícios como cereais, hortaliças, carnes. Na Era Vargas, traçam-se os mecanismos de abastecimento dos principais centros do país. No âmago da crise de 1929, o lema de Vargas é "produzir para abastecer o mercado interno", com o intuito de romper os laços de dependência do Brasil com o mercado externo.

Ao ampliar a intervenção do Estado no setor privado, acreditava-se poder afastar o Brasil da crise mundial e reorganizar a economia brasileira. Melhorar a distribuição de renda seria o meio de permitir maior consumo interno da produção (ibidem:82). Cabe destacar que, a partir dos anos 1930, as empresas estatais desempenharam (por intermédio da substituição das importações) papel central no processo de industrialização. A partir desse momento, a participação governamental direta na produção de bens e provisão de serviços cresce sistematicamente (Tavares de Almeida, 1999).

O processo de industrialização e de urbanização aumenta a demanda por alimentos frescos. Com a criação do Sistema Nacional de Crédito 
Rural (SNCR), em 1965, multiplica-se rapidamente o volume de hortigranjeiros comercializados nas cidades. No final da década de 1960, o governo identificou um grande estrangulamento na distribuição desses produtos. As negociações eram feitas presencialmente e ao ar livre, sem um local adequado e sem qualquer tipo de controle: ocorriam perdas, os produtos ficavam ao relento e os caminhões criavam enormes engarrafamentos nos centros urbanos. O governo criou, então, um grupo de trabalho, por intermédio do Decreto no $61.391 / 1967$, com a prioridade de regularizar o comércio de produtos de "primeira necessidade". Para as FLVs, houve um esforço de modernização de estruturas de comercialização com mercados regionais, Centrais de Abastecimento e mercados terminais. O intuito era evitar crises de abastecimento e oscilações de preço. Pelo Decreto no 67.750/1969 foi criado o Grupo de Modernização do Abastecimento (Gemab), responsável pelos estudos de viabilidade (Mourão, 2007).

A distribuição de alimentos frescos tem um marco regulatório com a criação das Centrais de Abastecimento no Brasil, no início da década de 1970, pela Lei no 5.727 de novembro de 1971. Em maio de 1972, foi criado o Sistema Nacional das Centrais de Abastecimento (Sinac), pelo Decreto no 70.502/1972, com a prioridade de reduzir custos de comercialização, organização e ainda melhorar os produtos e serviços de classificação e padronização (idem, ibidem). Os atores que vão ocupar as centrais são os atacadistas então atuantes nos mercados públicos (Linhares e Silva, 1979).

O projeto de mercados atacadistas foi arquitetado no âmbito do I Plano Nacional de Desenvolvimento (PND), vigente de 1972 a 1974. Em junho de 1974, foi extinto o Gemab, e suas atribuições foram transferidas para o Conselho Nacional de Abastecimento (Conab), o qual teve vida curta, sendo suas funções assumidas pelo Conselho Monetário Nacional (CMN). Para a elaboração dos projetos, o país conta com a assessoria de organismos internacionais, como a Organização das Nações Unidas para Agricultura e Alimentação (FAO, em inglês Food and Agriculture Organization of the United Nations). Nesse período, são contratadas grandes empresas de engenharia do setor de construção. Segundo Mourão (2007), o Conab trouxe engenheiros e arquitetos para dirigir as Ceasas. Além do projeto técnico de construção, esses profissionais assumiriam a direção das Ceasas, dado o entendimento de que "seria mais fácil a um profissional de engenharia ou arquitetura entender de comercialização do que um profissional de comercialização fa- 
zer um curso de engenharia" (ibidem:3). Estamos diante do manufactoring control, conforme Fligstein (1990).

Na primeira metade da década de 1970, foram implementados mercados do produtor com o intuito de melhorar as condições de comercialização das zonas produtoras. Na área do varejo, foram criados hortomercados ${ }^{12}$ com o intuito de disponibilizar hortigranjeiros a um preço mais acessível. Nesse momento, estavam em operação 34 Ceasas (áreas urbanas), 32 mercados do produtor (zonas produtoras) e 157 equipamentos varejistas (26 hortomercados, 50 sacolões $^{13}$, 59 varejões ${ }^{14}$, entre outros) (Mourão, 2007). Como observa Tavares de Almeida (1999), as empresas públicas eram quase sempre mais poderosas do que seus reguladores. Além disso, era possível constatar a fraqueza dos órgãos setoriais de regulação, não havia um mecanismo de controle do complexo do setor produtivo estatal. No final da década de 1970, esse setor era uma "caixa-preta", sendo o governo desconhecedor do montante de seus ativos e de suas dívidas.

As alterações na economia internacional, depois do segundo choque do petróleo, trouxeram o ajuste econômico para a pauta do dia; o controle das empresas estatais se apresenta como medida para enfrentar a crise inflacionária. O mecanismo mobilizado para tanto foi a criação da Secretaria de Controle das Empresas Estatais (Sest), com o objetivo de conhecer e controlar os gastos dessas empresas. Ao longo dos anos 1980, com o crescimento da inflação, o governo recorreu ao controle de preços e tarifas como parte do esforço de estabilização (Tavares de Almeida, 1999). Houve uma suspensão de investimentos também no setor de hortigranjeiros, e a proibição do reajuste de tarifas (como uma das anunciadas medidas de combate à inflação) implicou a descapitalização das Centrais de Abastecimento (Mourão, 2007).

O Sinac operava como um intermediador entre as Ceasas tanto nas diretrizes quanto nas inovações propostas. No Decreto no 93.611/1986, a Cobal transfere o controle acionário para os respectivos estados e municípios. Em caso de discordância dos donatários, as Ceasas poderiam ser privatizadas. O processo de transferência é de responsabilidade do Conselho Interministerial de Privatização (CIP) $)^{15}$. As Ceasas, a partir do fim do Sinac, experimentaram destinos diversos e consequências nefastas previstas pelos técnicos se concretizaram: cessão de áreas de expansão para terceiros, omissão, proliferação de intermediários (os quais especulam com os produtores), varejo tumultuando o atacado, 
degradação física das instalações, estagnação da classificação, padronização e embalagem, entre outros (idem, ibidem).

Conforme declaração dos técnicos, a perda da unidade sistêmica, com a extinção do Sinac, dificultaria o estabelecimento de qualquer medida de âmbito nacional - padronização, classificação, embalagens, inspeção, tabelamento de preços. Por sua natureza de "ponto de encontro", seria praticamente impossível que cada caminhão carregado que saísse de uma Central de Abastecimento (com uma norma e um padrão específicos) e entrasse em outra pudesse ser inspecionado sob os mesmos critérios. Após tentativa fracassada de renegociação da dívida com a participação do BNDES (Banco Nacional de Desenvolvimento Econômico e Social) e com o início da discussão da privatização, as Ceasas entram na lista do $\mathrm{PND}^{16}$, fato considerado pelos técnicos do setor um equívoco: a estrutura das Ceasas compreende tão somente um ponto de encontro e a atividade ali realizada já era de cunho privado; o braço estatal comportava a administração do complexo, a coleta e a divulgação de informações.

Em 1988, os dirigentes das Ceasas constituíram a Associação Brasileira das Centrais de Abastecimento (Abracen) como tentativa de manter as propostas do Sinac. Em 2005, por intermédio do Ministério da Agricultura, foi criado o Programa Brasileiro de Modernização do Mercado Hortigranjeiro (Prohort), coordenado pelo Conab, com o intuito de revitalização das Ceasas ${ }^{17}$.

\section{A Ceasa em Operação}

A comercialização de hortaliças no Brasil ocorre dentro das Ceasas, embora nos últimos anos as grandes redes supermercadistas tenham construído centrais de distribuição próprias. Segundo o Regulamento de Mercado (Ceasa/SC, 1990), não há interferência do poder público nas negociações e na formação de preços. Cabe aos técnicos tão somente o gerenciamento do espaço e das atividades, como em um condomínio (Lourenzani e Silva, 2004:389).

As Ceasas asseguram a "liberdade de entrada e saída" (conforme o modelo da economia neoclássica). A chegada de produtos para negociação obedece apenas à conveniência de compradores e vendedores, em negociações que seguem, segundo os técnicos, o Regulamento de Mercado. A partir do final da década de 1980, como já citado, com o desmonte do Sinac, surge a figura do "intermediário": ele compra FLVs 
dos produtores e revende minutos mais tarde dentro da própria Central, em geral para donos de quitandas, pequenos mercados, restaurantes, entre outros. Esse procedimento não é alvo de punição pelo regulamento e enfraquece ainda mais a condição de negociação do agricultor. Nas demais Ceasas, mantém-se o mesmo modelo de Regulamento de Mercado, o qual segue as especificações da Lei no 5.727 de novembro de 1971, complementada pelo Decreto no 70.502/1972.

O Regulamento de Mercado prevê um espaço denominado como permanente dos permissionários (atacadistas e outros prestadores de serviços) e o espaço dos pavilhões reservado aos agricultores, chamado de Mercado Livre do Produtor (MLP). Em algumas centrais, a exemplo da Companhia de Entrepostos e Armazéns Gerais de São Paulo (Ceagesp) e da Ceasa Campinas, esse espaço é definido apenas como Mercado Livre (ML), já que a maioria de seus ocupantes deixou de ser produtor, dedicando-se exclusivamente à atividade de comercialização de produtos ${ }^{18}$.

Na Ceasa /SC, observa-se que a distribuição do espaço no MLP é desfavorável aos agricultores: eles estão dispostos linearmente dentro de três grandes pavilhões (um agricultor ao lado do outro) e não podem observar as negociações, exceto as de seu vizinho do lado. Caso o agricultor não tenha vendido seus produtos nas primeiras horas do dia, a tendência é que o preço caia, ou seja, que ele aceite uma oferta por acreditar que está sem opção. Os frequentadores "fortes" da Ceasa/SC (conforme técnico entrevistado) são as centrais de compra dos grandes supermercados. Eles também entram e negociam com os agricultores como qualquer outro comprador, chegando mesmo a operar como os intermediários anteriormente mencionados (Silva-Mazon, 2006). O leilão, lembrando a definição de Weber (2004), que seria a maneira de garantir o encontro entre vendedores e compradores, não é privilegiado nem mesmo é item do regimento de mercado. Os leilões "formarão matéria de regulamento específico" (Ceasa /SC, 1990, art. 36, §1으). Esse regulamento impõe severas penalidades aos boxistas e agricultores que não saldarem suas dívidas com as Centrais de Abastecimento. No entanto, nenhuma punição está prevista para aqueles que não pagam os agricultores. Nesse assunto, ante os atos de compra e venda e pagamento direto entre usuários e clientela, cabe à Ceasa /SC ${ }^{19}$ tão somente o papel de "simples espectadora" (art. 36, § 2ㅇ), o que, argumentamos, torna vulnerável a condição do agricultor. Podemos sugerir aqui a au- 
sência da coação apontada por Weber (2004) como necessária para o funcionamento do mercado.

Os agricultores classificam as condições de recebimento como péssimas: quinze, trinta ou até sessenta dias de prazo (ou no fim da safra, como no caso dos atacadistas de tomate da Ceagesp) e com frequentes calotes. A compra realizada é aquela observada por Garcia-Parpet (2003) como "compra não firme", ou ainda, denominada no Brasil, "compra consignada", "compra especulativa" ou "preço por fazer"20: o agricultor primeiro entrega seus produtos sem a definição do preço (e com a nota fiscal em branco) e só terá acesso a essa informação depois da realização da venda pelo atacadista a seu cliente final (Lourenzani e Silva, 2004:391).

O proprietário de uma pequena rede supermercadista de Florianópolis nos chamou a atenção ao se declarar um cliente fiel e que sempre "paga" os produtos que adquire na Ceasa; como se o compromisso de pagamento fosse uma característica "extraordinária" de sua relação com os produtores. O problema da falta de pagamento aparece no funcionamento de outras Ceasas e na relação de atacadistas com agricultores que compram diretamente nas áreas de produção (Silva-Mazon, 2006). Aqui nos referimos a Durkheim para afirmar que essa relação entre compradores e vendedores pode se caracterizar como um contrato injusto; há uma parte mais forte do que a outra e bens e serviços não são trocados de maneira justa e de acordo com o seu valor. O contrato consensual que caracteriza as sociedades modernas, conforme Durkheim (1983), ainda não contempla os agricultores.

Durkheim afirma que trocas injustas podem ser explicadas por astúcia, habilidade, utilização manhosa das situações desfavoráveis, o que faz com que a consciência social se contraponha ao contrato injusto. Esse fenômeno se repete nos constantes calotes aos agricultores que comercializam na Ceasa/SC. Isso nos foi relatado por um técnico entrevistado que fala dos acontecimentos do final da década de 1970 e que permanecem, trinta anos depois, um problema atual. O não pagamento ao agricultor é uma constante do mercado e atravessa o tempo ${ }^{21}$. Em pesquisa com produtores de tomate e frequentadores da Ceasa/SC, nós constatamos que há uma forma de oposição dos agricultores ao não pagamento, como reação ao "contrato injusto", expressa no preenchimento das caixas com galhos, frutos ruins, entre outros. 
Cabe uma observação acerca do contexto das centrais. O aparato público ineficiente constatado pelos autores da NEI pode ser posto em dúvida dado que essa situação pouco poderia diferir a não ser em presença de pesados investimentos no setor. A suspensão de investimento talvez encontre amparo no clima das reformas liberalizantes como fruto da concepção de controle predominante.

Na década de 1980, inicia-se o movimento de acordos multilaterais com a Rodada Uruguai do Acordo Geral de Tarifas e Comércio (Gatt, em inglês General Agreement on Tariffs and Trade) da Conferência das Nações Unidas sobre Comércio e Emprego, precursor da OMC. Nessa década, a América Latina entra no sistema agroalimentar de dimensão mundial. Conforme argumenta Wilkinson (2004), o ajuste dos diversos países ao ambiente pós-Rodada Uruguai é marcado pela substituição de importações por estratégias de crescimento orientadas para a exportação. Todos os países em desenvolvimento experimentam um padrão de desregulamentação interna e banalização da entrada dos IDEs com uma reforma legal favorável aos investimentos estrangeiros; a prioridade é para o desenvolvimento da capacidade de exportação de alimentos processados (Wilkinson, 2004).

Nas décadas de 1980 e 1990, os países em desenvolvimento acompanham as tendências dos países desenvolvidos no que se refere à segmentação de produtos. Novos níveis de bem-estar econômico exigem da indústria agroalimentar inovação e segmentação com uma estratégia multiproduto. As empresas diversificam tanto para captar a demanda mais volátil e segmentada quanto para se adaptar às demandas logísticas do grande varejo que conta com a ECR. Entramos aqui na era da concepção de controle baseada no marketing e nas vendas, de acordo com Fligstein (1990). O aumento do varejo de larga escala foi analisado como uma consequência negativa para o setor da indústria alimentar (Wilkinson, 2002:334).

\section{Padrões de Difusão da Grande Rede Supermercadista}

Segundo Reardon, Timmer e Berdegué (2004), a América Latina tem liderado as mudanças do setor supermercadista nas regiões em desenvolvimento. A entrada de empresas transnacionais é orientada pelas fusões e aquisições. Em uma primeira onda, no início dos anos 1980 e antes dos IDEs, redes nacionais amplas compram lojas independentes e redes regionais. Na segunda onda, entre o início e a metade da década 
de 1990, a consolidação do setor supermercadista toma lugar por intermédio de aquisições pelas firmas norte-americanas e europeias estimuladas pela saturação de seus respectivos mercados locais. Nessa segunda onda, as empresas transnacionais compraram muitas das grandes redes domésticas; investimentos norteados pelos IDEs (Reardon e Berdegué, 2002:378).

Apenas um pequeno número de supermercados existia na maioria dos países em desenvolvimento durante os anos 1980 e o início de 1990. O capital era essencialmente doméstico, os supermercados eram situados nas maiores cidades e em bairros mais ricos (Reardon, Timmer e Berdegué, 2004:172). Em 2000, esse número salta para 50\%-60\% na América Latina (Reardon e Berdegué, 2002:377). Essa região, com exceção do Chile, experimentou, em uma única década, o mesmo desenvolvimento da rede supermercadista que os Estados Unidos viveram em cinco décadas (Reardon, Timmer e Berdegué, 2004:170).

No Brasil, o desenvolvimento do setor alimentar está dividido em três períodos, conforme Alexander e Lira Silva (2002). O primeiro período é marcado pela criação da Associação Brasileira de Supermercados (Abras) em 1968, ano em que os supermercados são reconhecidos como categoria diferenciada do varejo de alimentos e com incidência tributária à parte. A partir desse momento, a atividade de supermercados e de autosserviço é regulamentada ${ }^{22}$. Há uma mudança na cobrança de impostos, incentivos de crédito, taxas de juros reduzidas e prazos de pagamento estendidos (Belik, 2005). Na segunda fase, no início dos anos 1970, os IDEs surgem no cenário brasileiro; a rede Makro chega ao país em 1972 e o Carrefour, em 1975²3. A terceira e última fase marca o final dos anos 1990 e conta com a introdução de cartões de crédito, marcas próprias e o desenvolvimento das tecnologias de informação e comunicação (TICs) (Alexander e Lira Silva, 2002). Intensifica-se o movimento de fusões e aquisições, com participação marcante da rede varejista europeia ${ }^{24}$ (Rocha e Dib, 2002). Essa é a fase correspondente à concepção de controle da financeirização, segundo Fligstein (1990).

No que tange às tendências mundiais na distribuição de FLVs, a ênfase de nutricionistas e autoridades da saúde com relação ao consumo de produtos não industrializados (particularmente frutas e vegetais) poderia constituir-se em uma ameaça ao papel do varejo, em virtude da debilidade de fornecimento de atacadistas tradicionais e de funcionamento das Centrais de Abastecimento públicas. Contudo, dados re- 
centes mostram como a rede varejista se adaptou à oferta de FLVs, criando suas próprias centrais de distribuição (Wilkinson, 2002).

\section{PADRÕES DE SEGURANÇA E QUALIDADE EM CONSTRUÇÃO}

Supermercados, como estratégia de sobrevivência, competem para conquistar consumidores. Essa conquista acontece pelo corte de custo, pela constância na entrega, pela geração de qualidade e pela diversidade (Reardon e Berdegué, 2002:378). Para o setor de FLVs, as reclamações dos atacadistas especializados se referem ao funcionamento do atacado tradicional (como as Centrais de Abastecimento): ausência de informação e de padronização, baixa qualidade dos produtos, técnicas de colheita e controle de pós-colheita que deixam a desejar (Reardon, Timmer e Berdegué, 2004:173). Interessante observar que estas são as dificuldades anunciadas pelos técnicos das Ceasas no Brasil no final da década de 1980 no sentido de uma crônica da tragédia anunciada no momento do desmonte do Sinac. O discurso da comunidade dos engenheiros oriundos da esfera pública não encontra eco; o discurso vindo do mercado se apresenta como motivo para soluções urgentes e como competência da esfera privada.

A rede supermercadista de grande porte se afasta parcialmente do atacado tradicional e estabelece quatro pilares para o sistema de compra: atacadistas especializados; compra centralizada pelos centros de distribuição; suprimento assegurado e consistente com fornecedores preferenciais; padrões privados de qualidade e segurança impostos aos fornecedores (idem, ibidem).

Os supermercados investem na forma de apresentação dos produtos: menos a granel e mais embalados, pré-processados, agroindustrializados e orgânicos (Guivant, 2003a). As FLVs funcionam como estratégia de marketing e âncora das lojas na conquista e na fidelização dos clientes, bem como na geração de lucros. De maneira semelhante ao mercado de moluscos franceses, também aqui os distribuidores (supermercados) mobilizam uma indeterminação do mercado a seu favor. O vazio das normas de classificação e padronização (as quais deixaram de existir com o desmantelamento do Sinac) será preenchido pelos padrões da rede supermercadista. Detalhamos esse processo com o exemplo da cadeia do tomate ${ }^{25}$.

Os cultivares de tomate mais comercializados no Brasil são Carmen e Débora, ambos da Sakata Seed ${ }^{26}$. A característica principal desse tipo 
de semente é a homogeneidade e a firmeza dos frutos, que se tornam mais resistentes aos longos percursos no transporte (as caixas de tomate atravessam vários estados brasileiros nas diferentes safras); isso não significa superioridade em qualidades organolépticas e sanitárias.

Conforme relato de técnicos da Ceasa e agricultores, o tipo de semente é uma imposição dos atacadistas / distribuidores, que demandam melhores condições e menor quebra para a distribuição do produto ${ }^{27}$. Essa exigência encontra eco na indústria de sementes, atualmente concentrada em alguns grandes grupos: Dupont (maior indústria mundial), Monsanto (segunda maior corporação de sementes), Novartis (fusão Sandoz/Ciba-Geigy), Aventis, Dow Agro Science, AstraZeneca (fusão da Zeneca com o grupo farmacêutico Astra) e Sakata Seed. Neste artigo, abordamos os direitos de propriedade, conforme Fligstein (2001a). Wilkinson e Castelli (2000) destacam o clamor pela abertura comercial dos países em desenvolvimento e, em 1991, há forte pressão norte-americana quando da preparação do Acordo sobre os Direitos de Propriedade Intelectual Relacionados ao Comércio (Trips, em inglês Trade-Related Aspects of Intellectual Property Rights) da OMC.

O Brasil apresenta, nesse mesmo ano, seu projeto de Lei de Patentes, que estendia os direitos monopólicos de propriedade intelectual aos processos relacionados a alimentos; e, em 1996, a nova Lei de Patentes foi aprovada. No mesmo período, ocorre a tramitação da Lei de Proteção de Cultivares, liberando apropriação privada sobre cultivares de plantas por empresas de melhoramento genético; as duas leis entram em vigor em 1997 (ibidem:11). A partir da implementação dessas leis, observa-se, no Brasil, uma tendência de concentração no setor de produção de sementes por parte de empresas transnacionais junto a uma estagnação na produção de sementes melhoradas pelo setor público. Somado a isso, nos últimos anos a Empresa Brasileira de Pesquisa Agropecuária (Embrapa) perdeu parceiros que operam como franqueados exclusivos das transnacionais. Aparece como tendência no setor a redução da produção nacional de sementes com a deterioração do setor (ibidem:81).

Além do investimento em sementes por parte do produtor, há o uso de insumos químicos. Esse procedimento se inicia com a liberação do crédito rural na década de 1970 . O crédito para compra de insumos e máquinas, antes "supervisionado" por técnicos agrícolas, passa a ser tão somente "orientado", ou seja, os agricultores ficam livres para adqui- 
rir e aplicar a quantidade de insumos químicos que desejarem. Os impactos da intensificação do uso de insumos na saúde dos agricultores não são detectados pela vigilância sanitária (seja na notificação dos óbitos, seja nos atendimentos médicos), conforme a informação de técnicos da Companhia Integrada do Desenvolvimento Agropecuário de Santa Catarina (Cidasc) entrevistados. Investigando a aplicação dos agrotóxicos e a percepção de riscos à saúde entre agricultores, Julia Guivant (2003b) mostra que uma prática muito difundida entre eles é a de não respeitar os períodos de carência dos agrotóxicos aplicados (intervalo mínimo entre uma aplicação e outra para garantir a não contaminação), pois os agricultores percebem perdas financeiras caso não usem insumos químicos em quantidades acima do recomendado. No entanto, não visualizam os prejuízos à saúde, o que essa autora chama de "fatalismo químico"28 (Guivant, 1994:52).

O mercado de FLVs está contemplado no Regulamento de Defesa Sanitária Vegetal (RDSV), Decreto nํ24.114/1934, na Lei dos Agrotóxicos, Lei no 7.802 de julho de 1989, e no Decreto no 98.816/1990. A fiscalização no Estado de Santa Catarina fica a cargo da Cidasc ${ }^{29}$, conforme Lei no 11.069 de 1998 e alterada pela Lei no 13.238 de $2004^{30}$.

As exigências da legislação quanto às FLVs consideram os riscos associados à saúde (delimitação do número de aplicações de agrotóxicos) e ao meio ambiente (normas de descarte das embalagens que ficam sob responsabilidade do fabricante). As medidas sanitárias visam, entre outras, limitar os riscos de contaminação humana com agrotóxico, restringindo o número de aplicações, em particular próximo ao momento da colheita.

As normas de salubridade, a despeito do aparato legal e das visitas feitas aos agricultores pelos técnicos, não implicam nenhum tipo de restrição à comercialização. Conforme técnicos e agricultores entrevistados no Estado de Santa Catarina, como a exigência dos atores do mercado é somente com relação à aparência do fruto, os agricultores buscam garanti-la ${ }^{31}$. A ausência de restrições à comercialização parece indicar que a qualidade sanitária é somente aquela exigida pelos atores de mercado dominantes (atacadistas e redes supermercadistas) e a quantidade de agrotóxicos nas FLVs é pouco relevante nas decisões desses atores. Hernandez, Reardon e Berdegué (2007) analisaram produtores que vendem diretamente aos supermercados na Guatemala: além de serem mais capitalizados e mais especializados, mantêm uma 
prática de uso excessivo no que diz respeito aos pesticidas e aos fungicidas.

Outro elemento fundamental do campo da distribuição das FLVs é a sazonalidade. Voltemos ao tomate para falar do assunto. No Estado de Santa Catarina, como no restante do Brasil, há produção sazonal em diferentes épocas do ano, o que faz com que Centrais de Abastecimento e redes varejistas recebam produtos de diferentes estados brasileiros. A chegada ao consumidor, porém, faz com que o produto seja visto como homogêneo ao longo de todo o ano, embora a região de origem e a técnica de produção possam apresentar diferenças.

A região serrana do estado, por seus aspectos climáticos (baixas temperaturas o ano todo), é o local mais favorável ao plantio do tomate, com a taxa de aplicação de agrotóxicos mais baixa do que em qualquer outra região do estado, conforme dados do II Zoneamento Agroecológico e Socioeconômico do Estado de Santa Catarina (Icepa/SC, 2000). Se essa condição diferenciada da produção serrana estivesse vislumbrada na apresentação do produto no mercado, o consumidor teria chance de optar por um produto com menor quantidade de agrotóxicos. Além disso, antes de produzir apenas na entressafra de outros estados, a região teria condições de abastecer o mercado em outros períodos do ano; pelo menos para alguns cultivares. A Lei de Zoneamento é um dos aspectos da constituição dos direitos de propriedade, conforme Fligstein e Mara-Drita (1996). Nesse caso da não aplicação do zoneamento agrícola, os agricultores serranos ficam vulneráveis: nos momentos de excesso de produção nas regiões mais próximas dos centros compradores, a venda dos produtos dessa região fica comprometida.

Passamos aqui a vislumbrar a qualidade - no que diz respeito ao tomate - como um problema que clama por soluções que não são globais, mas justamente locais, e que supõem, por um lado, o engajamento de atores locais e, por outro, a revisão da legislação ambiental no sentido de que a verificação dos produtos não ocorra apenas nas áreas de produção, mas também na esfera da comercialização, no sentido de fundar novos princípios de relação entre maneiras de produzir e a qualidade do produto, conforme já observado no mercado de moluscos francês (Dubuisson-Quellier, 2003).

Se definirmos a qualidade de mercado como "o resultado do trabalho realizado pelos atores do mercado, do produtor ao consumidor, con- 
sistindo em construir os dispositivos fornecidos por seus atores para atribuir características aos produtos" (idem, ibidem: 102), podemos dizer que, no caso das FLVs, em particular do tomate, a qualidade de mercado se limita à qualidade que interessa aos atores mais potentes do mercado. Tal definição pouco diz sobre a qualidade organoléptica e sanitária ${ }^{32}$ dos frutos e considera esses produtos dentro dos mercados de maneira homogênea (Dubuisson-Quellier, 2003). Mesmo que as características do produto possam variar - modo de produzir, clima, solo, frequência de aplicação dos agrotóxicos -, elas desaparecem na entrada do produto na esfera da circulação.

A análise apresentada aqui abre espaço para duas observações sobre os padrões de segurança e qualidade. Primeiro, a ideia de que a tendência à homogeneização do sistema agroalimentar responde, entre outras, à demanda de um consumidor exigente cai por terra. No caso do tomate, o consumidor tem à sua disposição um produto em geral bastante contaminado. Segundo, se as diferentes dimensões de qualidade e o grau de toxicidade do produto fossem contemplados no mercado de FLVs, isso tornaria o ambiente propício para se desfazer da ideia de que a comercialização desses produtos só pode se submeter a um enquadramento jurídico de escala global, como preconiza a grande rede supermercadista.

Abordamos agora os números invisíveis do setor de produtos frescos. Mainville et alii (2005) relatam a ausência de informações sobre os volumes comercializados de FLVs no setor atacadista e no varejo. A partir do momento em que o Sinac foi desmantelado, não há uma maneira de registrar para o país o volume de hortifrutigranjeiros comercializado. Em pesquisa anterior (Silva-Mazon, 2006), técnicos da Secretaria da Agricultura e do Departamento de Crédito Agrícola do Banco do Brasil relatam as dificuldades de levantamento do volume produzido e comercializado pelos produtores de FLVs, já que grande parte das vendas ocorre de maneira informal ou pelo método de "notas fiscais em branco", como já citado. A única maneira de levantar esses dados seguramente, segundo eles, é buscar, nos pontos de venda de sementes o volume adquirido por cada agricultor. Ou seja, perdas de safra, produtos estragados e os não pagamentos são dificilmente contabilizados. Argumentamos que essa invisibilidade do setor pode contribuir para o "contrato injusto": não há estatísticas nas Ceasas, não é possível saber quanto um agricultor produziu, quanto vendeu, quanto recebeu e, portanto, qual é o ganho real ou o prejuízo em cada safra. 
Aqui voltamos às instituições de mercado propostas por Fligstein (2001b) à luz da ideia do contrato injusto. Nas regras de troca do setor alimentar, o agricultor não tem seus direitos respeitados. Se a condição de comercialização para os agricultores não encontra amparo no Regulamento de Mercado da Ceasa, essa situação não se torna mais confortável quando falamos da grande rede varejista que passa a negociar diretamente com os primeiros. Além da exigência de melhoramento na forma de entrega e qualidade das frutas, as modalidades dos contratos desvendam o desequilíbrio no poder de barganha (dado que as grandes redes varejistas detêm grande parcela do mercado): assimetria de poder nas negociações, prazos de recebimento longos, descontos de perdas dos produtos não vendidos, impedimento por parte da rede varejista para que o produtor crie sua marca ou selo próprio (Lourenzani e Silva, 2004:391-392).

O pequeno produtor é pressionado, de um lado, pela indústria de sementes, que aumenta constantemente o valor unitário do produto colocado no mercado, e, de outro, pelos atacadistas e pela rede varejista, que tentam transferir os riscos de perdas ao agricultor pagando em geral só aquilo que conseguem vender. Com relação às estruturas de governança e aos direitos de propriedade, o ambiente legal propício para fusões e aquisições, via organismos multilaterais ou bilaterais, consolida e concentra rapidamente tanto o setor da distribuição quanto o da produção, ocorrendo o mesmo com as redes supermercadistas transnacionais e o setor da indústria de sementes. Observa-se, nas regras de troca do mercado de FLVs, um deslocamento parcial de negociações intermediadas por atacadistas para um novo modelo dos sistemas privados (centrais de distribuição da rede supermercadista), o qual mantém a condição de dominação sobre o agricultor.

\section{CONCLUSÕES}

Neste artigo, foram analisadas as mudanças no terreno institucional do abastecimento alimentar brasileiro no que tange aos produtos frescos, focando a construção dos padrões de qualidade e segurança. A Nova Economia Institucional (NEI) lê a elaboração crescente de padrões e grades privados no setor alimentar como movimento de eficiência na cadeia e inexorável. Em oposição a esse grupo de autores, à luz da Nova Sociologia Econômica (NSE), é possível apontar os aspectos político-culturais da construção desses padrões. 
O Estado, como réu da crise econômica da década de 1980, foi julgado ineficiente e centralizador em diversos setores, incluindo o de abastecimento alimentar nas análises próximas à NEI. Os autores da NSE convidam a uma análise que mostra o Estado como ator fundamental na construção do mercado de frutas, legumes e verduras, mesmo que sua ação seja a de retirar investimentos das Centrais de Abastecimento públicas a partir das reformas liberalizantes.

A leitura dos padrões de qualidade e segurança da NEI segue a ideia de North de custos de transação altos internos e externos às firmas, fenômeno considerado típico para países em desenvolvimento. A análise pouco meritória do agricultor pode reforçar regras de troca desiguais nos termos de Durkheim, "contratos injustos" -, ambiente no qual os agricultores são vítimas da inadimplência.

A construção do MCE mostra o rumo cultural dos padrões de segurança e qualidade, o qual pode ajudar a entender as mudanças ocorridas no Brasil. As mudanças trazidas pelo MCE focaram mais as regras de troca do que as estruturas de governança e direitos de propriedade. $\mathrm{O}$ Brasil viveu uma experiência diversa de abertura com foco nos direitos de propriedade e estruturas de governança. Olhar essas particularidades do fenômeno no Brasil mais de perto pode ser uma boa pista de pesquisa.

O caso do tomate sugere a investigação da interatuação Estado e mercado como pista de pesquisa para explicar a condição dos pequenos agricultores produtores de FLVs. Não há evidências de que os padrões privados estabelecidos pela rede supermercadista sejam os mais eficientes.

(Recebido para publicação em novembro de 2007)

(Reapresentado em novembro de 2008)

(Aprovado para publicação em abril de 2009) 


\section{NOTAS}

1. Questionando os pressupostos da Teoria Econômica Neoclássica, os autores da NSE defendem o postulado dos mercados como construções sociais. O autor que cunha a expressão NSE é Mark Granovetter, propond o o conceito de redes para explicar o enraizamento social dos mercados. Das críticas a esse autor surgem a abordagem político-cultural dos autores aqui trabalhados, Pierre Bourdieu e Neil Fligstein, e a abordagem cultural que explora os significados coletivos na definição de estratégias econômicas (Wanderley, 2002). A abordagem político-cultural enfatiza o papel do Estado como construtor de mercados, os atores como desiguais e as normas e classificações pensadas junto com os interesses antagônicos que as produzem (Fligstein, 2001b; Bourdieu, 2005).

2. Esse autor analisa a produção de móveis em Cuanajo, empreendimento dos índios mexicanos. Constata a ilegalidade da madeira fornecida, níveis de educação baixos, uma atmosfera de furtos entre os empregados e os problemas com a polícia local como fatores que aumentam tanto os custos de transação internos quanto os externos (Acheson, 1994). Boselie, Henson e Weatherspoon (2003:1155) observam como desafio a construção da confiança entre supermercados e agricultores em países em desenvolvimento, em virtude da volatilidade dos preços, do isolamento dos agricultores com relação aos mercados (regiões distantes e poucos canais de comunicação) e do desequilíbrio entre os atores. Pequenos produtores, além de menores, são atores menos poderosos na cadeia.

3. Os G\&S exprimem um conjunto de especificações técnicas, termos e princípios de classificação e rotulagem. Eles incluem regras de medida estabelecida por regulação ou autoridade (standards) e um sistema de classificação baseado em atributos quantificáveis (grades). Eles dizem respeito à qualidade (aparência, limpeza, sabor); segurança (resíduo de pesticida ou hormônio artificial, presença de micróbios); autenticidade (garantia de origem geográfica ou uso de um processo tradicional); e, por último, excelência do processo produtivo (com respeito à saúde do trabalhador e sua segurança ou contaminação ambiental) (Reardon e Farina, 2002:414).

4. Castro (2007) propõe pensar o desenvolvimento tecnológico da agricultura brasileira em duas fases. A primeira, do período da Revolução Verde (tripé pesquisa - extensão - crédito rural, difusores de uma tecnologia intensiva em insumos e máquinas), e uma segunda fase, que demandaria qualidade e desenvolvimento sustentável na organização dos mercados, em particular o das commodities.

5. Accountability diz respeito à prática de prestação de contas de atos públicos por parte dos agentes governamentais à sociedade (Pereira, 1997).

6. Financeirização pode ser compreendida como a prevalência absoluta do ponto de vista financeiro sobre outras considerações de estratégias da empresa e a focalização do retorno dos investimentos dos acionistas (Useem, 1993 apud Grün, 2003).

7. No caso brasileiro, Grün (2003) mostra como um novo ambiente legal toma forma a partir da década de 1990, expresso no movimento de fusões e de incorporações de empresas e reforçado pela Lei das Sociedades Anônimas e o "novo mercado de capitais", de 1999. Esse movimento aparece traduzido na expressão "governança corporativa" e está relacionado ao processo de privatização, o qual teve como consequências o esfacelamento de grupos sociais que se haviam formado em torno das organi- 
zações estatais, tão bem como o arrefecimento da defesa dos princípios sindicais. O mesmo autor pondera que a defesa da governança corporativa ficou abalada pelos escândalos da Enron, Tyco e da Arthur Andersen. Esta última, como uma das maiores empresas de auditoria externa, atuava na vigilância de outros grupos empresariais e falhou em sua própria. No caso mexicano, o objetivo da liberalização como eliminador do comportamento rent seeking não o eliminou, ao contrário, estimulou-o por intermédio da discreta alocação de oportunidades para o setor privado (Pereira, 1997).

8. Conforme argumenta Fligstein (2002), essa afirmação coincide com a análise de Harrison White; porém, aquilo que este considera um processo econômico aquele considera um processo político.

9. O Codex Alimentarius é um fórum internacional de normalização sobre alimentos. Foi criado em 1962 pela união da Organização das Nações Unidas para a Agricultura e a Alimentação (FAO) com a Organização Mundial da Saúde (OMS). Suas normas têm como finalidade proteger a saúde da população, assegurar práticas equitativas no comércio regional e internacional de alimentos, criar mecanismos internacionais dirigidos à remoção de barreiras tarifárias, fomentar e coordenar todos os trabalhos que se realizam em normalização (ver Inmetro, disponível em http: / / www.inmetro. gov.br/comites/ccab.asp. Acessado em 8/11/2007).

10. Concordando com Fligstein e Mara-Drita, e a partir da economia heterodoxa, Chang (2004) faz uma interpretação histórica sobre as estratégias de desenvolvimento dos países industrializados com respeito à mobilização política e às instituições em questão. Chang mostra que, quando esses países estavam em processo de desenvolvimento, eles protegeram suas indústrias e deram enormes subsídios às exportações práticas hoje condenadas na lista das "boas políticas" elaboradas pelo Consenso de Washington. Esses países estariam dispostos a "chutar a escada" para os PBRs, pela qual eles próprios subiram para atingir a condição em que se encontram hoje.

11. A ocorrência de saques em São Paulo e em outras cidades obriga o Comissariado a regular o comércio varejista sem, porém, tocar nos interesses dos atacadistas (Linhares e Silva, 1979).

12. Os hortomercados eram mercados varejistas de produtos hortícolas, geralmente associados a um supermercado da Companhia Brasileira de Alimentos (Cobal) (Mourão, 2007).

13. Na década de 1970, o Sinac identificou, em Minas Gerais, uma iniciativa de comerciantes na venda de um mix de frutas e hortaliças a um preço único por quilo; eram os sacolões. A partir dos anos 1980, eles receberam apoio do poder público, inclusive da administração das Ceasas, e alcançaram êxito em âmbito nacional (Mourão, 2007).

14. Os varejões tratavam da abertura das Ceasas uma vez por semana e também quando não havia comercialização do atacado para o consumidor adquirir produtos diretamente do produtor ou de comerciantes atacadistas. Os preços eram administrados pela Ceasa, que estabelecia um teto máximo inferior ao preço praticado no varejo da cidade (Mourão, 2007).

15. Em 1981, o governo estabeleceu por decreto a Comissão Especial de Desestatização com o intuito de limitar a criação de novas estatais. A ideia de que as empresas estatais podiam ser entregues ao setor privado passou a fazer parte do discurso do governo e das elites em geral. Em 1985, o primeiro governo democrático criou o progra- 


\section{Marcia da Silva Mazon}

ma de privatização e substituiu a Comissão Especial pelo Conselho Interministerial de Privatização (CIP) (Tavares de Almeida, 1999).

16. O Congresso não participou nem opinou sobre a criação da Sest. Essa situação mudou com a Constituição de 1988, quando o Congresso e o Judiciário ganharam novas prerrogativas, e o Executivo perdeu a possibilidade de legislar por decreto. A Lei noㅡ 8.031/1990, que criou o PND, não só fazia parte do pacote de medidas provisórias (MPs) do Plano Collor como, depois de aprovada pelo Congresso, foi modificada por MPs na gestão Fernando Henrique Cardoso até ser transformada em nova lei em 1997, Lei no 9.491/1997 (Tavares de Almeida, 1999).

17. O Prohort foi elaborado por técnicos da Ceasa Minas (Contagem/MG) e da Universidade Federal de Viçosa (UFV), em 1997, e conta com o apoio do Programa das Nações Unidas para o Desenvolvimento (PNUD). O intuito é reconstruir um sistema nacional das Ceasas. Ele foi oficializado no quadro da Cobal pela Portaria nํㅜ 171 de março de 2005 (http:/ / www.abracen.org.br. Acessado em 10/1/2007). O primeiro passo foi implementar um banco de dados com informações dos 62 mercados atacadistas brasileiros. Em 2005, a Ceasa / MG doou o software criado para a inserção de dados, e o Conab desenvolveu um segundo software para a extração de informações. Em 2006, foi criado um portal: http:/ / www.ceasa.gov.br.

18. Os dados de Andreuccetti et alii (2005:392) mostram que grandes produtores de tomate fornecedores da Ceagesp se transformaram em atacadistas quase sempre especializados nesse mesmo produto. Esses autores observam uma concentração na comercialização do tomate na Ceagesp por um número reduzido de atacadistas.

19. Um diretor técnico da Ceasa/MG, entrevistado em 2005, relatou que o funcionamento do leilão (via painel eletrônico) era fundamental para a rotina dessa Central. Nós a visitamos em 2008 e o painel eletrônico estava fora de funcionamento.

20. Conforme Garcia-Parpet (2003), na compra firme, compradores são obrigados a depositar uma caução e os preços são estabelecidos e negociados ao longo do leilão, e não combinados a posteriori.

21. Em análise do momento atual, Pereira (2001) pondera que, no mercado atacadista do tomate, os ganhos do produtor não passam de 30\% do total pago pelo consumidor.

22. Até 1950, a legislação que regulamentava o comércio de alimentos era favorável às pequenas lojas de secos e molhados e às padarias, as quais se caracterizam como negócios familiares. Esses pequenos empreendimentos adotavam como rotina o funcionamento nos fins de semana e até às $20 \mathrm{~h}$. O trabalho assalariado da grande rede varejista não encontrava amparo na lei (Belik, 2005).

23. A rede Carrefour, a partir de 1999, começa um processo de aquisições no Brasil: Lojas Americanas, Planaltão, Roncetti, Mineirão, Rainha, Dallas e Continente. Hoje é a segunda empresa no ranking da Abras com um faturamento de 12,5 bilhões em 2005 (Super Hiper, 2006).

24. A participação dos supermercados na distribuição de alimentos cresceu de $26 \%$ para 85\% entre 1970 e 1996 (Rojo, 1998). Em 1994, as vinte maiores empresas do Brasil representavam $56 \%$ do faturamento total dos supermercados com $16 \%$ de capital externo. Em 2001, os IDEs saltaram para 57\% das vendas do setor nas vinte maiores empresas (ver Abrasnet, disponível em http://www.abrasnet.com.br. Acessado em 1ㅇ/8/2007). Cabe lembrar que, enquanto em 1990 nenhum varejista foi incluído na lista das quinhentas maiores empresas globais da revista Fortune, em 2002 eles eram 
mais de cinquenta nesse grupo (Oosterveer, Guivant e Spaargaren, 2007). Em 2007, o maior varejista no Brasil é o Carrefour, seguido do Pão de Açúcar e do Wal-Mart (Facchi e D'Ambrosio, 2007). O grupo chileno Cencosud anunciou, no final de 2007, a aquisição da rede sergipana GBarbosa, a maior rede de supermercados do Nordeste (Valor, 2007).

25. Por ser procurado com maior frequência pelo consumidor, o tomate é o produto que comanda a variação de preço das outras hortaliças. É também responsável pelo maior volume financeiro de comercialização dentro das Ceasas (Della Giustina, 2005). As reflexões com relação à cadeia do tomate podem se estender às outras hortaliças, dado que atacado e varejo utilizam padrões semelhantes de comercialização para os diferentes cultivares (Lourenzani e Silva, 2004).

26. O setor de sementes também experimenta participação significativa dos IDEs. As empresas multinacionais chegam ao Brasil entre as décadas de 1960 e 1970: Cargill, Limagrain e Asgrow em 1971, Dekalb em 1978 e Ciba-Geigy em 1979. A indústria de sementes tem um número expressivo de empresas atuantes, mas a atividade de pesquisa é dominada por poucas firmas, sendo que permanece relevante a participação do Centro Nacional de Pesquisa da Embrapa (Wilkinson e Castelli, 2000:53).

27. Parte dos dados apresentados aqui teve como base pesquisa feita em meu mestrado em 2004 e 2005 sobre a montagem do mercado do produtor de Urubici/SC. Foram realizadas entrevistas semiestruturadas com agricultores do município e frequentadores da Ceasa, técnicos da Ceasa/SC e da Ceasa/MG, da Empresa de Pesquisa Agropecuária e Extensão Rural de Santa Catarina (Epagri), do Instituto de Planejamento em Economia Agrícola de Santa Catarina (Icepa), da Cidasc, funcionários e gerentes de redes supermercadistas atuantes em Santa Catarina (Silva-Mazon, 2006).

28. A Agência Nacional de Vigilância Sanitária (Anvisa) iniciou, em 2001, o Programa de Análise de Resíduos de Agrotóxicos em Alimentos (Para) seguindo metodologia preconizada pelo Codex Alimentarius e inova ao colher as amostras dentro dos supermercados. Em 2008, as análises atingiram quinze estados e dezessete itens de FLVs. A análise engloba ingredientes ativos de agrotóxicos e limites máximos permitidos para cada cultura (ver Anvisa, 2008).

29. A Companhia Integrada do Desenvolvimento Agropecuário de Santa Catarina (Cidasc) é vinculada à Secretaria da Agricultura. O estado está dividido em zonas agrícolas e uma equipe técnica desse órgão visita as propriedades regularmente.

30. Ver www.cidasc.sc.gov.br. Acessado em 1응 /2007.

31. As especificidades com relação à aparência das FLVs estão contempladas em manuais que os supermercados utilizam como guia de orientação para recepção e verificação das mercadorias nas lojas. Um manual de FLVs da rede supermercadista detalha a padronização do produto ( $\mathrm{pH}$, peso, cor, aspecto, condição de armazenamento, temperatura, defeitos graves e leves aceitáveis), além de informações da posição das FLVs na loja, distribuição no setor (jogo de cores, layout) (Comper, s/d).

32. Na intenção de subsidiar políticas públicas de segurança alimentar, a cúpula mundial de alimentação (uma arena de representação dos países ligados à Organização das Nações Unidas (ONU)) adotou, como consenso sobre o tema, que essas políticas devem contemplar produção e distribuição conectadas a valores fundamentais, como saúde, higiene, autenticidade e solidariedade. O eixo ecológico ou orgânico diz respeito à qualidade do alimento (Camargo Almeida et alii, 2006). 


\section{REFERÊNCIAS BIBLIOGRÁFICAS}

ACHESON, James M. (1994), "Transaction Costs and Business Strategies in a Mexican Indian Pueblo", in Anthropology and Institutional Economics. Maryland, University Press of America, pp. 143-163.

ALEXANDER, Nicolas e LIRA SILVA, Marcelo. (2002), “Emerging Markets and the Internationalization of Retailing: The Brazilian Experience". International Journal of Retail and Distribution Management, vol. 30, no 6, pp. 300-314.

ANDREUCCETTI, Caroline et alii. (2005), "Caracterização da Comercialização de Tomate de Mesa na Ceagesp: Perfil dos Atacadistas". Horticultura Brasileira, vol. 23, no 2, pp. 324-328.

ANVISA (Agência Nacional de Vigilância Sanitária). (2008), Programa de Análise de Resíduos de Agrotóxicos em Alimentos (Para). Disponível em http://www.anvisa. gov.br. Acessado em 10/12/2008.

ATHUKORALA, Prema-Chandra e JAYASURIYA, Sisira. (2003), "Food Safety Issues, Trade and WTO Rules: A Developing Country Perspective". The World Economy, vol. 26, no 9, pp. 1395-1418.

BELIK, Walter. (2005), Supermercados e Produtores: Limites, Possibilidades e Desafios. Trabalho apresentado no Grupo de Trabalho Globalização dos Sistemas Agroalimentares e Agendas Alternativas, XII Congresso Brasileiro de Sociologia, Belo Horizonte, 31 de maio-3 de junho.

BOSELIE, David, HENSON, Spencer e WEATHERSPOON, Dave. (2003), “Supermarket Procurement Practices in Developing Countries: Redefining the Roles of the Public and Private Sectors". American Journal of Agricultural Economics, vol. 85, no 5, pp. 1155-1161.

BOURDIEU, Pierre. (1993), “Esprits d'Etat. Genèse et Structure du Champ Bureaucratique". Actes de la Recherche en Sciences Sociales, vols. 96/97, pp. 49-62.

. (1996), "É Possível um Ato Desinteressado?", in P. Bourdieu, Razões Práticas. São Paulo, Papirus.

. (2005), "O Campo Econômico". Revista Política e Sociedade, vol. 6, pp. 15-57.

CAMARGo AlmeIdA, L. M. M. et alii. (2006), "Políticas Públicas, Redes de Segurança Alimentar e Agricultura Familiar: Elementos para a Construção de Indicadores de Eficácia". Estudos Sociedade e Agricultura, vol. 14, no 2, pp. 205-234.

CASTRO, Ana Célia. (2007), O Catching-up do Sistema Agroalimentar Brasileiro: Fatos Estilizados e Molduras Conceituais. Trabalho apresentado no XXXI Encontro Anual da Associação Nacional de Pós-Graduação em Ciências Sociais (Anpocs), Caxambu, MG, 22-26 de outubro.

CEASA/SC (Centrais de Abastecimento do Estado de Santa Catarina). (1990), Regulamento de Mercado.

CHANG, Ha-Jun. (2004), Chutando a Escada. Estratégia de Desenvolvimento em Perspectiva Histórica. São Paulo, Editora da Unesp (tradução de Luiz Antônio de Oliveira Araújo). 
COCHOY, Franck. (2002), "Une Petite Histoire du Client, ou la Progressive Normalisation du Marche et de l'Organisation". Sociologie du Travail, vol. 44, pp. 357-380.

COMPER (Rede Comper de Supermercados). (s/d), Manual do Programa de Formação FLV. Manual interno.

DELLA GIUSTINA, José Eláudio. (2005), Sintese Anual da Agricultura de Santa Catarina 2003-2004/Tomate. Instituto Cepa/SC, pp.121-128.

DIMAGGIO, Paul J. e POWELL, Walter W. (1991), “The Iron Cage Revisited Institutional: Isomorphism and Collective Rationality in Organization Fields", in P. J. DiMaggio e W. W. Powell (eds.), The New Institutionalism in Organizational Analysis. Chicago, University of Chicago Press.

DOUGLAS, Mary. (1996), Cómo Piensan las Instituciones. Madrid, Alianza Editorial.

DUBUISSON-QUELLIER, Sophie. (2003), “Confiance et Qualité des Produits Alimentaires: Une Approche par la Sociologie des Relations Marchandes". Sociologie du Travail, vol. 45, no 1, pp. 95-111.

DURKHEIM, Émile. (1983), Lições de Sociologia: A Moral, o Direito e o Estado. São Paulo, T. A. Queiroz/Edusp, pp. 156-201.

FACCHI, Claudia e D’AMBROSIO, Daniela. (2007), “Varejo ‘Grupo Compra Rede Paulista e Aproxima-se de Novo do Carrefour'”. Valor Econômico, Caderno Tendências e Consumo,1-4 de novembro.

FARINA, Elizabeth e REARDON, Thomas. (2000), "Agrifood Grades and Standards in the Extended Mercosur: Their Role in the Changing Agrifood System". American Journal of Agricultural Economics, vol. 82, no 5, pp. 1170-1176.

FLIGSTEIN, Neil. (1990), The Transformation of Corporate Control. Cambridge, Harvard University Press.

. (2001a), "Le Mythe du Marché". Actes de la Recherche en Sciences Sociales, vol. 139, pp. 3-12.

. (2001b), “Mercado como Política: Uma Abordagem Político-Cultural das Instituições de Mercado". Contemporaneidade e Educação, vol. 9, pp. 26-55.

. (2002), The Architeture of Markets. An Economic Sociology of Twenty-first-century Capitalist Societies. Princeton, Princeton University Press.

e MARA-DRITA, Iona. (1996), "How to Make a Market: Reflections on the Attempt to Create a Single Market in the European Union". American Journal of Sociology, vol. 102, pp. 1-33.

GARCIA-PARPET, Marie France. (2003), “A Construção Social de um Mercado Perfeito: O Caso de Fontaines-en-Sologne". Estudos Sociedade e Agricultura, no 20, pp. 5-44.

GRANOVETTER, Mark. (2003) [1985], “Ação Econômica e Estrutura Social. O Problema da Incrustação”, in R. Marques e J. Peixoto (orgs.), A Nova Sociologia Econômica. Oeiras, Celta.

GRÜN, Roberto. (2003), “Atores e Ações na Construção da Governança Corporativa Brasileira". Revista Brasileira de Ciências Sociais, vol. 18, no 52, pp. 141-163.

. (2005), “Apagão Cognitivo: A Crise Energética e sua Sociologia". DADOS, vol. 48, no 4, pp. 891-928. 


\section{Marcia da Silva Mazon}

GUIVANT, Julia S. (1994), "Percepção dos Olericultores da Grande Florianópolis (SC) sobre os Riscos Decorrentes do Uso de Agrotóxicos". Revista Brasileira de Saúde Ocupacional, vol. 82, no 22, pp. 47-57.

(2003a), “Os Supermercados na Oferta de Alimentos Orgânicos: Apelando ao Estilo de Vida Ego-Trip". Ambiente \& Sociedade, vol. 6, no 2, pp. 63-82.

(2003b), "Pesticide Use, Risk Perception and Hybrid Local Knowledge: A Case Study from Southern Brazil". International Journal of Sociology of Agriculture and Food, vol. 11, no 1 , pp. 41-51.

HALL, Peter A. e TAYLOR, Rosemary C. R. (2003), “As Três Versões do Neoinstitucionalismo". Lua Nova, no 58, pp. 193-224.

HERNÁNDEZ Ricardo, REARDON, Thomas e BERDEGUÉ, Julio. (2007). "Supermarkets, Wholesalers and Tomato Growers in Guatemala". Agricultural Economics, vol. 36, pp. 281-290.

HOLLERAN, Erin, BREDAHL, Maury E. e LOKMAN, Zaibet. (1999), "Private Incentives for Adopting Food Safety and Quality Assurance". Food Policy, vol. 24, pp. 669-683.

ICEPA/SC (Instituto de Planejamento em Economia Agrícola de Santa Catarina). (2000), SC-AGRO 2000/Informações da Agricultura Catarinense. Florianópolis, Secretaria de Estado do Desenvolvimento Rural e da Agricultura. CD ROM.

KRUEGER, Anne. (1990). "Government Failures in Development". Journal of Economic Perspectives, vol. 4, no 3, pp. 9-23.

LINHARES, Maria Yeda L. e SILVA, Francisco C. T. (1979), História Política do Abastecimento (1918-1974). Brasília, Binagri Edições (Coleção Estudos sobre o Desenvolvimento Agrícola, vol. 6).

LOURENZANI, Ana Elisa Bressan Smith e SILVA, Andréa Lago da. (2004), “Um Estudo da Competitividade dos Diferentes Canais de Distribuição de Hortaliças". Gestão e Produção, vol. 11, no 3, pp. 385-398.

MAINVILLE, Denise, ZYLBERSZTAJ, Decio, FARINA, Elizabeth e REARDON, Thomas. (2005), "Determinants of Retailers' Decisions to Use Public or Private Grades and Standards: Evidence from the Fresh Produce Market of São Paulo, Brazil". Food Policy, vol. 30, pp. 334-353.

MARQUES, Eduardo César. (1997), “Notas Críticas à Literatura sobre Estado, Políticas Estatais e Atores Políticos". BIB, vol. 43, pp. 67-102.

MOURÃO, Ivens R. A. (2007), “Análise de um Mercado Hortigranjeiro e Sugestões de Intervenção". Disponível em http://www.minas.ceasa.mg.gov.br. Acessado em $10 / 10 / 2007$.

NORTH, Douglass C. (1991), "Institutions". Journal of Economic Perspectives, vol. 5, no 1, pp. 97-112.

OOSTERVEER, Peter, GUIVANT, Julia e SPAARGAREN, Gert. (2007), "Shopping for Green Food in Globalizing Supermarkets: Sustainability at the Consumption Junction", in J. Pretty et alii (eds.), Handbook of Environment and Society. London, Sage.

PEREIRA, Carlos. (1997), “Em Busca de um Novo Perfil Institucional do Estado: Uma Revisão Crítica da Literatura Recente". BIB, no 44, pp. 81-102. 
PEREIRA, Leda B. de Oliveira. (2001), Caracterização das Unidades Produtivas com Tomate Estaqueado na Bacia do Rio das Pedras (Mogi-Guaçu/SP), Dissertação de mestrado, Faculdade de Engenharia de Alimentos, Universidade Estadual de Campinas (Unicamp), Campinas, SP.

POPKIN, Barry (2006), “Technology, Transport, Globalization and the Nutrition Transition Food Policy". Food Policy, vol. 31, pp. 554-569.

RAUD-MATTEDI, Cecile. (2005), "A Construção Social do Mercado em Durkheim e Weber. Análise do Papel das Instituições na Sociologia Econômica Clássica". Revista Brasileira de Ciências Sociais, vol. 20, no 57, pp. 127-142.

REARDON, Thomas e BERDEGUÉ, Julio. (2002), "The Rapid Rise of Supermarkets in Latin America: Challenges and Opportunities for Development". Development Policy Review, vol. 20, no 4, pp. 371-388.

REARDON, Thomas e FARINA, Elizabeth. (2002), "The Rise of Private Food Quality and Safety Standards: Ilustrations from Brazil". International Food and Agribusiness Management Review, no 4, pp. 413-421.

REARDON, Thomas, HENSON, Spencer e BERDEGUÉ, Julio. (2007), “Proactive Fast-tracking' Diffusion of Supermarkets in Developing Countries: Implications for Market Institutions and Trade". Journal of Economic Geography, vol. 7, pp. 399-431.

REARDON, Thomas, TIMMER, Peter e BERDEGUÉ, Julio. (2004), “The Rapid Rise of Supermarkets in Developing Countries: Induced Organizational, Institutional and Technological Change in Agrifood Systems". Journal of Agricultural and Development Economics, vol. 1, no 2, pp. 168-183.

REARDON, Thomas et alii. (2003), "The Rise of Supermarkets in Africa, Asia and Latin America". American Journal of Agricultural Economics, vol. 5, no 85, pp. 1140-1146.

ROCHA, Angela da e DIB, Luis Antonio. (2002), "The Entry of Wal-Mart in Brazil and the Competitive Responses of Multinational and Domestic Firms". International Journal of Retail and Distribution Management, vol. 30, no 1, pp. 61-73.

ROJO, Francisco J. G. (1998), “Pesquisa: O Comportamento do Consumidor nos Supermercados". Revista de Administração de Empresas, vol. 38, no 3.

SILVA-MAZON, Marcia da. (2006), A Construção Social do Mercado Olerícola na Ótica da NSE. Estudo de Caso em Urubici-SC. Trabalho apresentado no XXX Encontro Anual da Associação Nacional de Pós-Graduação em Ciências Sociais (Anpocs), Caxambu, MG, 24-28 de outubro.

SKOCPOL, Theda. (1996), "Bringing the State Back In Strategies of Analysis in Current Research", in P. Evans, D. Rueschemeyer e T. Skocpol (eds.), Bringing the State Back In. Cambridge, Cambridge University Press, pp. 3-37.

STEINER, Philippe. ( 2006), Les Marchés Agroalimentaires Sont-ils des “Marchés Spéciaux"? Palestra proferida no Centro Socioeconômico/UFSC. Mimeo.

SUPER HIPER. (2006), Panorama 2007 - Análises e Estatísticas. Revista da Abras.

TAVARES DE ALMEIDA, Maria Hermínia. (1999), “Negociando a Reforma: A Privatização de Empresas Públicas no Brasil”. DADOS, vol. 42, no 3, pp. 421-451. 
THÉRET, Bruno. (2003), “As Instituições entre as Estruturas e as Ações”. Lua Nova, vol. 58, pp. 225-255.

VALOR. (2007), Acon Lucra 280\% com Venda do GBarbosa. Caderno Tendências e Consumo, pp. b4, 8 de novembro.

WANDERLEY, Fernanda. (2002), “Avanços e Desafios da Nova Sociologia Econômica. Notas sobre os Estudos Sociológicos de Mercado". Sociedade e Estado. vol. 17, no 1, pp. 15-38.

WEBER, Max. (2004), Economia e Sociedade (4a ed.). Brasília, UnB, vol. I (tradução de R. Barbosa e K. E. Barbosa).

WILKINSON, John. (2002), “The Final Food Industry and the Changing Face of the Global Agrofood System: Up Against a New Technology Paradigm and a New Demand Profile". Sociologia Ruralis, vol. 42, no 7, pp. 329-347.

. (2004), "The Food Processing Industry, Globalization and Developing Countries". Journal of Agricultural and Development Economics, vol. 1, no 2, pp. 184-201.

e CASTELLI, Pierina G. (2000), A Transnacionalização da Indústria de Sementes no Brasil. Biotecnologias, Patentes e Biodiversidade. Rio de Janeiro, ActionAid. 


\section{ABSTRACT \\ Food Quality and Safety Standards in the Brazilian Institutional Scenario}

Private food quality and safety standards are emerging as "the" language of the food industry. The Brazilian market is experiencing the decline of the CEASAs, or Wholesale Produce Markets, and the expansion of supermarkets, including in the distribution of fresh produce. This growth is interpreted by the New Institutional Economy as the efficiency of private quality systems as compared to the purportedly inefficient public systems. Based on the political and cultural approach of the New Economic Sociology (NES), the article challenges the evidential nature of the institutions' efficiency, as well as the definition of quality and safety as neutral concepts. Based on the NES approach, these concepts can be seen as cultural constructs.

Key words: wholesale produce markets; supermarkets; safety and quality standards; new economic sociology; fresh produce

RÉSUMÉ

Modèles de Qualité et de Sécurité Alimentaire sur le Terrain Institutionnel Brésilien

Les systèmes de qualité et de sécurité privés sont la référence officielle du marché alimentaire et imposent des règles et des modèles qui autorisent la circulation des aliments tout au long de la chaîne de production et distribution. Pour le marché brésilien, on observe un déclin des centrales d'achat et la croissance sensible des supermarchés y compris dans la distribution des produits frais. Cette croissance est considérée par la Nouvelle Économie Institutionnelle comme l'expression de l'efficacité des systèmes privés de qualité face à l'inefficacité du système public. À partir de l'approche politique et culturelle de la Nouvelle Sociologie Économique (NSE), il s'agit de discuter le caractère évident de l'efficacité des institutions privées ainsi que la définition du concept de qualité et de sécurité en tant que catégorie neutre. Sur la base de la référence proposée, les deux concepts, "efficacité" et "qualité", sont des constructions culturelles.

Mots-clés: centrales d'achat; supermarchés; modèles de sécurité et de qualité; Nouvelle Sociologie Économique; produits frais 